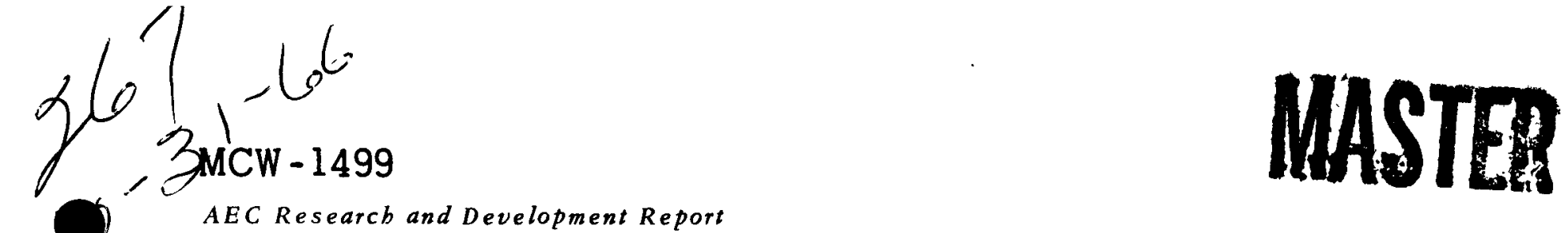

AEC Researcb and Development Report

\title{
ALKALINE-PEROXIDE COLORIMETRIC METHODS FOR THE DETERMINATION OF URANIUM
}

RELEASED FOR ANNOUNCEMENT

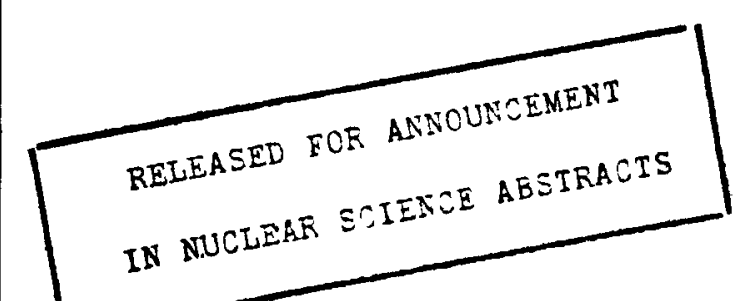

August 1, 1966

\section{WELDON SPRING PLANT}

$$
\begin{aligned}
& \text { MALLINCKRODT OWEMICAL WORKS } \\
& \text { URANIUM DIVISION } \\
& \text { COntract NO. W-IA-IOB-Eng-8 }
\end{aligned}
$$




\section{LEGAL NOTICE}

This report was prepared as on account of Government sponsored work. Neither the United States, nor the Commission, nor any person oeting on behalf of the Commission:

A. Makes ony warronty or representation, expressed or implied, with respect to the accuracy, completeness, or usefulness of the information contained in this report, or that the use of any information, apparatus, method, or process disclosed in this report may not infringe privately owned rights; or

B. Assumes any liabilities with respect to the use of, or for damages resulting from the use of any information, opparatus, mothod, or process disclosed in this report.

As used in the above, "person octing on behalf of the Commission" includes ony employee or contractor of the Commission, or employee of such contractor, to the extent that such employee or contractor of the Commission, or employee of such contractor propares, dissominates, or provides access to, any information pursuant to his employment or contract with the Commission, or his employment with such contractor.

Printed in USA. Price $\$ 3.00$. Available from the Clearinghouse for Federal Scientific and Technical Information, National Bureau of Standards, U. S. Department of Commerce, Springfield, Virginia 


\section{DISCLAIMER}

This report was prepared as an account of work sponsored by an agency of the United States Government. Neither the United States Government nor any agency Thereof, nor any of their employees, makes any warranty, express or implied, or assumes any legal liability or responsibility for the accuracy, completeness, or usefulness of any information, apparatus, product, or process disclosed, or represents that its use would not infringe privately owned rights. Reference herein to any specific commercial product, process, or service by trade name, trademark, manufacturer, or otherwise does not necessarily constitute or imply its endorsement, recommendation, or favoring by the United States Government or any agency thereof. The views and opinions of authors expressed herein do not necessarily state or reflect those of the United States Government or any agency thereof. 


\section{DISCLAIMER}

Portions of this document may be illegible in electronic image products. Images are produced from the best available original document. 


$$
\begin{aligned}
& \text { MCW-1499 I.C. } .75 \\
& \text { UC-4, Chemistry } \\
& \text { (TID-4500, 37th Edition) }
\end{aligned}
$$

TOPICAL REPORT

\section{ALKALINE-PEROXIDE COLORIMETRIC METHODS FOR} THE DETERMINATION OF URANIUM

\section{RELEASED FOR ANNOUNCEMENT \\ IN NUCLEAR SCIENTE ABSTRACTS}

by

\section{H. F. Waldron}

August 1, $1966 \ldots$

\section{Mallinckrodt Chemical Works \\ Uranium Division \\ Weldon Spring, Missouri}

\section{LEG AL NOTICE}

This report was prepared as an account of Government sponsored work. Neither the United States, nor the Commission, nor any person acting on behalf of the Commission

A. Makes any warranty or representation, expressed or implied, with respect to the accuracy. completeness, or usefulness of the tnformation contained in this report, or that the use racy. completeness, or usefulness of the tnformation contained in this report, or that the use
of any information, apparatus, method, or process disclosed in this report may not infringe of any information, appar

B. Assumes any liabilities with respect to the use of, or for damsges resulting from the use of any information, apparatus, method, or process disclosed in this report.

As used in the above, "person acting on behalf of the Commisston" includes any employee or contractor of the Commission, or employee of such contractor, to the extent that such employee or contractor of the Commission, or employee of such contractor prepares, disseminates, or provides access to, any information pursuant to his employment or contract with the Commission, or his employment with such contractor. 
Number of Copies

Internal

10

External in accordance with TID-4500, 48th Edition Category UC-4, Chemistry

Special

Cincinnati Area Office

Mr. C. L. Karl

Division of Production, Washington

Mr. W. Devine

Dow Chemical Company, Rocky Flats

Dr. L. A. Matheson

Oak Ridge Operations office

Mr. E. B. Klser, Jr.

Mr. B. M. Robinson

Dr. R. E. Wedemeyer

1

1

1

334 
ALKALINE-PEROXIDE COLORIMETRIC METHODS FOR THE DETERMINATION OF URANIUM

by

H. F. Waldron

\section{ABSTRACT}

A comprehensive review of the literature on the determination of uranium by measuring the absorbance of the uranium-peroxide species in an alkaline medium is presented. The factors affecting the accuracy and precision of the measurement are discussed according to whether sodium carbonate, sodium carbonate and sodium hydroxide, sodium hydroxide, or other reagents are used to supply the alkaline medium. The sodium hydroxide system is concluded to be the best for general applications.

In all but some special situations, 400 ms is the optimum wavelength for measuring the uranium-peroxide color. Increased sensitivity can be obtained at shorter wavelengths, but the loss of accuracy and/or the necessity for close $\mathrm{pH}$ and reagent concentration control nullifies the advantage. Longer wavelengths yield reduced sensitivity with no compensation.

The sodium hydroxide system is the most rugged and permits complete standardization of reagent volumes without previous measurements and/or adjustments. The high $\mathrm{pH}$ provides better spectral absorbance characteristics and higher tolerance levels of molybdenum, thorium, vanadium, and $z$ irconium than the other systems. The sodium carbonate system requires more operator care, but it is less sensitive to the presence of arsenic, barium, cerium, cobalt, iron, magnesium, manganese, nickel, silicon, tin, and titanium. The higher permissible levels for the elements which precipitate in an alkaline medium is due to less uranium occlusion in the presence of carbonate. To a large extent, this advantage may be obtained in the sodium hydroxide system if the peroxide is added before the solution is made alkaline. When the system contains both sodium hydroxide and sodium carbonate, the spectral absorbance characteristics approach those of the sodium hydroxide system while the interferences become similar to those of the sodium carbonate system. In comparison to the sodium hydroxide system, however, considerably more caution is required to obtain reliable results. A comparison of interferences in the three major systems is shown in Table $I$. 
Table I

Summary of the Elements Investigated for Interference in Alkaline-Peroxide Methods for Uranium Determination and Their Approximate Concentration Limits

Element $\frac{\text { Approximate Maximum Concentrations W1thout Interferences, mg. } / 100 \mathrm{ml} .}{\mathrm{Na}_{2} \mathrm{CO}_{3} \text { Method, } 425 \mathrm{mu} \cdot \mathrm{Na} \mathrm{NO}_{3}-\mathrm{NaOH} \text { Method, } 400 \mathrm{mu} \cdot \mathrm{NaOH} \text { Method, } 425 \mathrm{mu} \cdot}$

\begin{tabular}{|c|c|c|c|}
\hline $\mathrm{Ag}_{\mathbf{g}}$ & 0.1 & $\cdots$ & 0.1 \\
\hline $\begin{array}{l}\text { Au } \\
\text { Al }\end{array}$ & $\begin{array}{l}5.0 \\
\text { None }\end{array}$ & $\ddot{50}$ & $\ddot{\text { None }}{ }^{a}$ \\
\hline As & None $e^{a}$ & $\ldots$ & $\begin{array}{l}8.0 \\
8.0\end{array}$ \\
\hline B & None & $\ldots$ & None $e^{a}$ \\
\hline $\mathrm{Ba}$ & None & $\ldots$ & 1.0 \\
\hline $\mathrm{Ca}$ & $\ldots \ldots$ & $\ldots$ & 1.0 \\
\hline $\mathrm{Ce}$ & None $a, b, c$ & $\ldots$ & 0.5 \\
\hline Co & None ${ }^{a}$ & $\ldots$ & 0.1 \\
\hline $\mathbf{C r}$ & $0.1^{c}$ & 0.01 & $0.1^{c}$ \\
\hline $\mathrm{Cu}$ & 0.2 & $10^{d}$ & 0.5 \\
\hline $\mathrm{Fe}$ & None $e^{a}$ & $20^{d, e}$ & 0.5 \\
\hline $\mathrm{Ga}$ & None $^{a}$ & $\ldots$ & None ${ }^{a}$ \\
\hline $\mathrm{Hg}^{\mathrm{f}}$ & $\ddot{\cdots} \cdot$ & $\cdots$ & 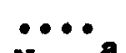 \\
\hline In & None & $\cdots$ & None ${ }^{a}$ \\
\hline$M 8$ & None ${ }^{a}$ & ... & 10 \\
\hline Mn & 9 & 0.1 & 0.1 \\
\hline Mo & $1.0^{c}$ & $5-10$ & $8.0^{c}$ \\
\hline $\mathbf{N b}$ & $8-10^{c}$ & r. & $8-10$ \\
\hline N1 & None $^{a}$ & $20-50^{e}$ & 0.5 \\
\hline $\mathbf{P}$ & None $^{8}$ & $\ldots$ & None $^{a}$ \\
\hline $\mathbf{P b}$ & Nonea & 20 & None $^{a}$ \\
\hline Pd & 0.5 & $\cdots$ & ... \\
\hline Pt & None $^{\mathrm{a}}$ & $\cdots$ & $\ldots$ \\
\hline$S 1$ & None $e^{a}$ & $\ldots$ & 8.0 \\
\hline Sn & 7.0 & $\cdots$ & 1.0 \\
\hline Sr & None $^{a}$ & •.. & $\ddot{\cdots} \cdot$ \\
\hline Th & 0.5 & $\therefore \ldots$ & 8.0 \\
\hline T1 & $8.0^{c}$ & $\bullet \bullet$ & 0.1 \\
\hline $\mathbf{\nabla}$ & $1.0^{c}$ & $\ldots$ & 50 \\
\hline W & $8-10$ & $\ldots$ & $\ldots$ \\
\hline $\mathbf{Z n}$ & None $^{a}$ & 20 & None ${ }^{a}$ \\
\hline $\mathbf{Z r}$ & 9 & .... & None $^{a}$ \\
\hline
\end{tabular}

a. "None" Indicates no interference was observed when $100 \mathrm{ml}$. of a solution containing $10 \mathrm{mg}$. of uranium and $10 \mathrm{mg}$. of " $E$ " was analyzed for uranium.

b. This is belleved to be an isolated case and even a small amount may interfere due to formation of a colored cerium species.

c. These materials may be expected to give more interference at $400 \mathrm{mu}$. than at the wavelength listed.

d. These values may be considerably lower in most systems, due to a catalytic effect.

e. This amount can be tolerated if one carbonate separation is made.

f. Reduced to metallic state in alkaline-peroxide systems. 
\begin{tabular}{l} 
ALKALINE-PEROX IDE COLOR METR IC METHODS FOR \\
THE DETERMINAT ION OF URANIUM \\
\hline
\end{tabular}

by

H。 F。 Waldron

\section{INTRODUCTION}

The reaction of uranium with hydrogen peroxide or sodium peroxide in an alkaline medium to produce a colored solution was reported by Aloy $(2,37)$ in 1902 and described more thoroughly by Rosenheim and Daehr (54) in 1929. The spectral absorbance characteristics of the solutions thus produced have provided the bases for perhaps the most universally used methods of uranium measurement and, since 1940, numerous reports on the subject have appeared. Much of the analytical work was conolucted simultaneously by independent groups, and variations in the resulting procedures are many. The purpose of this report is to summarize and evaluate these variations so that more intelligent and complete use of the methods may be made. The following discussion has been divided into four sections according to whether sodium carbonate, sodium carbonate and sodium hydroxide, sodium hydroxide; or other alkaline reagents were used to supply the basic medium necessary to form the colored uranium-peroxide complex. Since this report is intended for reference use, considerable duplication of information occurs in order to make each subsection relatively complete.

The nature of the colored species that are measured in these systems have recelved some attention, but most investigators have used the inconclusive method of isolating the reaction products. Disagreement is evident from the number of compounds obtained in this manner $(29,54,55,80,87)$. Corpel (12), however, has considered the species as they exist in solution and proposed $\mathrm{UO}_{5} \mathrm{H}^{-}$and/or $\mathrm{UO}_{5}=$, depending on the $\mathrm{pH}$ of the solution, as the colored complexes present.

\section{SODIUM CARBONATE-PEROX IDE METHOD}

From an analytical point of view, the sodium carbonate system is by far the oldest and until recent years it recelved considerably more attention than the others. Rosenheim and Daehr ( 54 ) reported in 1929 that the white amorphous precipitate produced when uranyl ion reacts with hydrogen peroxide in a slightly acidic solution would dissolve on the addition of sodium or ammonium carbonate. Furthermore, the intensity of the yellow color in the resulting solution was observed to vary directly with the uranyl ion concentration. A decade later Hackl (22) proposed that the reaction be used as the basis for the uranium determination in silicate rocks and presented considerable data on the specificity of the reaction with few details for actual application. 
The volume of literature on this method that has appeared since Hackl's report is difficult to evaluate because of the many variations in procedure and application. The particular procedure is especially important in this method because a weak base is used to provide the alkaline medium. This allows considerable pH fluctuation which may produce deleterlous effects as discussed in the appropriate subsections. An attempt has been made to include the essentials of a particular procedure when the data are believed to be affected by specific conditions or operations. For example, filtration of the alkaline solution prior to color development and the use of a bicarbonate-carbonate buffer is peculiar to the work reported by Huston (30) and must be considered in the interpretation of the results. The data in many of the reports on this method are inconclusive and frequently this is due to the wide band width and low sensitivity of the instruments used for measuring the color intensity.

In the carbonate method, the $\mathrm{pH}$ and the wavelengths at which the absorbance measurements are made are important. It 18 concluded that $400 \mathrm{m \mu}$ is the optimum wavelength and the instrument setting should be made with care since the absorbance is quite dependent on the wavelength in this region.

The pH should be as high as practical but closely controlled. This, of course, necessitates control of the carbonate concentration. Although reproducible results may be obtained at lower $\mathrm{pH}$ values, the maximum $\mathrm{pH}$, about 10.5-11.0, attainable in this system provides greater sensitivity and should be used if possible. In this respect, potassium carbonate may be preferred to the sodium salt because its greater solubility enables a higher concentration. The use of 10-15 ml. of $1 \mathrm{M}$ sodium carbonate in excess of that necessary for neutralization is usually satisfactory.

It appears that approximately $0.5 \mathrm{ml}$. of $30 \%$ hydrogen peroxide per $100 \mathrm{~m} 1$. of solution is the optimum amount. The concentration 1 imit will depend on the amount of uranium present and the carbonate concentration. An upper 1 imit results from excessive bubble formation, which occurs when $1.0 \mathrm{ml}$. or more of $30 \%$ hydrogen peroxide 18 added to $100 \mathrm{ml}$. of solution. Excessive peroxide concentrations also produce more rapid fading of the color.

\section{Absorption Spectra}

The lack of agreement among the reported absorption spectra for the uraniumperoxide species in a carbonate solution may usually be attributed to instrumental or procedural differences, or both. The definite absorption maxima reported for $340,(20) 350,(31) 400,(30)$ and $410-430 \mathrm{m \mu}$ (e) are really nonexistent for the uranium-peroxide species per se, but were observed because an incorrect blank or instrument of wide band width was used. Indications are that a maximum does exist in the vicinity of $300 \mathrm{~m} \mu$ 。 $(18,18,30,47,49,59)$ Reagent concentrations and $\mathrm{pH}$ have an effect on the characteristics of the absorption spectrum and are treated in separate sections of this report.

The spectral transmittance curves obtained with the Coleman Model 11 and Beckman Model DU spectrophotometers are shown In Figure 1。(30) The spectra shown are of uranium-peroxide solutions buffered at a $\mathrm{pH}$ of 9.9-10.4 with a carbonate-bicarbonate buffer and measured against water blanks in 19-mm. OD 
(approximate 16-mm。 ID) cylindrical and 1-cm。cells with the Coleman and Beckman instruments, respectively. For the data obtained with the Beckman instrument, a band width of approximately $1 \mathrm{m \mu}$ was used. Similar curves have appeared elsewhere $(19,49,59)$. Rider, et al. (49), have reported spectral transmittance curves for the reagents as shown in Figure 2. The data were obtained on a Beckman Model DU spectrophotometer using water blanks, $1-\mathrm{cm}$. cells, and a $1-\mathrm{m} \mu$ band width.

A variety of wavelengths have been used for measurements of the color intensity in the determination of uranium. Beer's law appears to be obeyed over the entire useable wavelength range, but at wavelengths shorter than $400 \mathrm{~m} \mu$ the reagent concentrations must be closely controlled. Ilnear analytical curves have been reported for $100 \mathrm{ml}$ of solution containing up to $10 \mathrm{mg}$ of uranium at $370 \mathrm{m \mu}$ (36) and $25 \mathrm{mg}$. at $425 \mathrm{m \mu}$ (30) when a Beckman Model DU spectrophotometer and $1-\mathrm{cm}$. cells were used. A slight deviation is noted above $15 \mathrm{mg}$. per $100 \mathrm{ml}$. at $425 \mathrm{m \mu}$ when a Coleman Model 11 instrument and 19-mm. cylindrical cells are used (30).

Raisen-Streden (47) reported that the molar absorbtivity for the uraniumperoxide system is not constant, but depends on the cell dimensions (70). Since this would be a contradiction to the universal law of Bouguer (frequently attributed to Lambert), it is assumed that the reported variations were actually inherent in the optical system employed. In addition, the use of a corresponding uranium solution, complete with all reagents except the peroxide, as a blank reduced the observed absorbance values. This blank was used to eliminate the interference of small amounts of chromate ion and to correct for the uranylcarbonate complex color. The latter correction is inappropriate since the species is not present in the solution contalning the peroxide. The Pulfrich photometer of Zeiss-Jena with a mercury lamp and the special filter 543 to obtain the mercury line of $436 \mathrm{m \mu}$ was used.

From the above information and variables yet to be discussed, it appears that $400 \mathrm{~m} \mu \mathrm{is}$ the optimum wavelength for analytical purposes. At this wavelength, the concentration range which may be allowed will depend on the cell dimensions and instrument used. An instrument providing a narrow band width is preferred.

\section{Effect of Reagent Concentration}

The effect of reagent concentration on the carbonate-hydrogen peroxide method for uranium has been mentioned in various reports $(2,0,20,30,44,47,49,50,51$, $52,58)$, but many investigators have falled to include sufficient data to make their information useable. In this discussion, therefore, only a limited number of reports are considered in detail.

Sodium Carbonate

The amount of sodium carbonate is said to affect not only the intensity but also the nature of the color $(2,9,20)$. According to Cassidy (9), the effects of this reagent are considerable, as shown in Figure 3, and of two types: (a) the wavelength of minimum transmission is shifted toward the red end of the spectrum with increased concentration of alkali, 
and (b) the percent transmission is decreased with increased concentration of alkali. A Cenco spectrophotelometer with a tungsten lamp and $1-\mathrm{cm}$. cells were used for the measurements. The spectral transmittance curves thus obtained actually do not support the stated conclusions because a blank containing all the solution materials except the hydrogen peroxide was used. What the curves actually show is the difference in transmittance of the uranium-carbonate and the uranium-peroxide complexes, with a host of reagent varlables present. They also serve to emphasize the erroneous data that may be obtained if an incorrect blank is used. A simflar shift in the wavelength of minimum transmittance has been reported for variations in the uranium concentration ( 2 ); but this is apparently due, at least in part, to the use of an excessive spectral band width. On the other hand, a relative indifference to the sodium-carbonate concentration has been reported for readings made at $400 \mathrm{m \mu}$ with a Beckman Model DU (49), at $420 \mathrm{m \mu}$ with a Klett-Summerson photoelectric colorimeter (50), and at $436 \mathrm{~m} \mu$ with a Pulfrich photometer (47).

One of the more thorough investigations of the effect of varied reagent concentrations was performed by Huston ( 30 ) who used the $425-\mathrm{m} \mu$ wavelength for measuring the color intensity. This study is peculiar in that a bicarbonate-carbonate buffer is used to stabilize the $\mathrm{pH}$ at 9.9 to 10.4. The use of this buffer, $0.756 \mathrm{M}$ in sodium carbonate and $0.356 \mathrm{M}$ in sodium bicarbonate, complicates the reagent concentration study. In the presence of $10 \mathrm{ml}$. of this buffer solution, an excess of $10 \mathrm{ml}$. of $1 M$ sodium carbonate per $100 \mathrm{ml}$. of solution was found to be a satisfáctory amount, and a variation of 1 - to $15-\mathrm{ml}$. excess had no effect on the results. More than $15 \mathrm{ml}$. resulted in slightly high results and an increased rate of fading. It should be noted that this seemingly wide variation in sodium carbonate solution is actually an addition to an already appreciable amount present in the buffer solution. Thus a range of $1-15 \mathrm{ml}$. of $1 \mathrm{M}$ sodium carbonate represents a total sodium carbonate concentration change of 0.085 to $0.22 \mathrm{M}$ when the solution, including $10 \mathrm{ml}$. of buffer, is diluted to a final volume of $100 \mathrm{ml}$. Although this shifts the sodium carbonate-sodium bicarbonate ratio from 2.4 to 6.3 , the $\mathrm{pH}$ remains within the specifled limits of 9.9-10.4. Absence of the buffer was found to give high results but a variation of 5 to $30 \mathrm{ml}$. of the buffer solution had no effect. Since acceptable results were obtained by this method, it is of interest to note that other investigators have found the presence of bicarbonate to be highly undesirable and to cause low results $(50,60,63,68)$. A more detailed discussion of the bicarbonate effect will be included in the interference section.

As implied by other reports $(34,69)$, it may be said that the sodium carbonate concentration is critical only with respect to its influence on the $\mathrm{pH}$. At $400 \mathrm{m \mu}$, this effect becomes non-existant at $\mathrm{pH}$ values above about 10.5. Therefore, close control of the carbonate concentration is not necessary either if a buffer is used to control the $\mathrm{pH}$ or if a minimum $\mathrm{pH}$ of 10.5 is maintained and the measurement made at $400 \mathrm{~m} \mu$. For the latter method, an excess, after neutralization 
of the sample, of $10-15 \mathrm{ml}$. of $1 \mathrm{M}$ sodium carbonate solution seems to be adequate except when impurities that tend to lower the $\mathrm{pH}$ are present. If the buffer system is used, the amount of carbonate necessary will depend on the concentration and type of the buffer.

\section{Hydrogen Peroxide}

Moderate peroxide concentration changes have no effect provided a suffictent amount to develop full color is used $(47,50)$. This amount would be expected to vary with uranium concentration and there is some indication that the amount needed decreases with increasing carbonate concentration (8). For $10 \mathrm{mg}$. of uranium in $100 \mathrm{~m} 1$. of solution, Huston (30) found that one $m 1$. of $3 \%$ hydrogen peroxide was sufficient and that excessive amounts could produce slightly high results and more rapid fading of the collor.

The optimum amount has been reported to be $5 \mathrm{ml}$ of $3 \%$ hydrogen per $100 \mathrm{ml}$. of solution (47). From all indications, this is perhaps the most desirable amount since it provides a sufficlent excess but does not overload the system to the point of interference. Although most of the literature concerning this system Involves measurement at $400 \mathrm{m \mu}$ or longer wavelengths, it should be noted that at shorter wavelengths the peroxide concentration is much more critical because of the absorbance of the peroxide itself.

The commercial $3 \%$ reagent has been observed to produce a yellow color when added to an alkaline solution $(2,51,52)$. This has not been reported for the $30 \%$ reagent.

\section{Other Reagents}

The addition of disodium phosphate (47) or ammonium nitrate (50) to the sodium carbonate system has been considered. Raisen-Streden (47) stated that the presence of phosphate effects an increased stability of the hydrogen peroxide in alkaline solutions and will reduce or eliminate the undesirable bubble formation. Accordingly, the addition of phosphate, as the disodium salt, was recommended; but the optimum concentration was not determined.

Roberts and Seath (50) reported that the sodium carbonate method is sensitive to variations in low-level nitrate concentrations. To swamp this effect, they added one $\mathrm{ml}$. of a saturated ammonium nitrate solution. In the small final volume of $10 \mathrm{ml}$. used in their procedure, this produced a relatively high ammonium nitrate concentration of about $85 \mathrm{mg}$. per $\mathrm{ml}$., and the addition of another $\mathrm{ml}$. was reported to have no effect. Huston (30) also studied the effect of ammonium nitrate and reported that up to; $0.2 \mathrm{~g}$. could be tolerated without interference when the final volume was $100 \mathrm{ml}$, or $2 \mathrm{mg}$. per $\mathrm{ml}$. An increase in concentration up to the highest concentration studied, $20 \mathrm{mg}$. per ml。, resulted in a continuous decrease in both $\mathrm{pH}$ and uranium recovery. This was attributed to interference of the ammonium ion by virtue 
of its effect on the $\mathrm{pH}$. It appears that the nitrate sensitivity reported by Roberts and Seath is in reality a $\mathrm{pH}$ effect caused by the ammonium lon. Thus, low levels of ammonium nitrate would have no effect on Huston's buffered system while the high levels used by Roberts and Seath would tend to stablize the $\mathrm{pH}$.

\section{Effect of $\mathrm{pH}$}

The $\mathrm{pH}$ of this system is necessarily closely allied with the sodium carbonate concentration as described in the preceding section.

The spectral characteristics of this system are intimately related to the pH and In general the absorbance varies directly with the alkalinity. At $400 \mathrm{~m} \mu$ the absorbance increases as the $\mathrm{pH}$ increases $(\theta, 30,62,63,69)$ unt11 a $\mathrm{pH}$ of 10.5-11.0 is reached $(62,63)$ where a pH-Independent system is established (48). A similar behavior has been observed at 365 and $435 \mathrm{~m} \mu(62,63)$. The pH-dependence of this system has led to misinterpretations by attributing direct interference to materfals such as ammonium nitrace and bicarbonate. In reality, these materials affect the colored uranium species only indirectly by their influence on the $\mathrm{pH}$, and if the $\mathrm{pH}$ can be properly adjusted, their presence should be tolerable.

Huston's (30) investigation of the interference of ammonium ion has provided some $\mathrm{pH}$-variation data for $425 \mathrm{m \mu}$. The system was stablized at a $\mathrm{pH}$ of 9.9-10.4 with a carbonate-bicarbonate buffer. The addition of increasing amounts of ammonium nitrate produced decreasing $\mathrm{pH}$ and uranium recovery values over the $\mathrm{pH}$ range of 9.3 to 10.1. Most other data available on pH-dependence was obtained during studies of other variables and it is difficult to isolate the $\mathrm{pH}$ effect. But, it is certain that the $\mathrm{pH}$ is important and that a minimum alkalinity, which apparently is at or near the maximum attainable with sodium carbonate, 18 necessary to eliminate $\mathrm{pH}$-dependence. A lower $\mathrm{pH}$ may be used with a loss in sensitivity, if the alkalinity is closely controlled. Occasionally this may be advantageous if it allows the presence of forelgn materials which prevent the attainment of a higher $\mathrm{pH}$ and which would otherwise have to be separated.

\section{Inter ferences}

Most reports have dealt with number of interferences pertinent to the analysis of particular samples. Because of the variations in procedure, which are inadequately described in many cases, it is difficult to compare the data given in different reports. In addition, many reports concerning this method offer little interference data because relatively pure solutions obtained from an ethyl ether $(8,20,24,31,51,58,64)$ or penta-ether $(5,8,11,14,17$-pentaoxaheneicosane $)(41,42)$ extraction were used.

Huston (30) has compiled the most complete single source of information. The elements treated were those found by spectrographic analysis to be present in chemical K-65, the carbonate leached residue from nitric acid digestion of 
pitchblende ore. Since most of the limits given in the following discussion are from this report, the procedure is given below: and especially the filtration and use of a buffer should be considered in the interpretation of the results. Unqualified data from other reports may be assumed to apply to methods involving excess sodium carbonate and no special treatment such as filtration or buffering.

The material under investigation was added to nitric acid solution containing $10 \mathrm{mg}$. of uranium. The solution was neutralized with IM sodium carbonate, and an excess of $10 \mathrm{ml}$. was added. The resulting solution was bolled, cooled, filtered, and diluted to $85 \mathrm{ml}$. Ten $\mathrm{ml}$. of a buffer solution $\left(0.765 \mathrm{M}\right.$ in $\mathrm{Na}_{2} \mathrm{CO}_{3}$ and $0.356 \mathrm{M}$ in $\left.\mathrm{NaHCO}_{3}\right), 0.5 \mathrm{ml}$. of $30 \% \mathrm{H}_{2} \mathrm{O}_{2}$, and sufficient water to give $100 \mathrm{ml}^{-}$were added. From the absorbance measured at $425 \mathrm{m \mu}$ on a Beckman Model DU spectrophotometer, against a water blank, the apparent amount of uranium was determined. The buffer provides $\mathrm{pH}$ of 9.9 to 10.4 .

Although the list of possible interferences in this system is quite oizable, the number that must be considered as serious for any given type of sample is not overwhelming. A summary of the behavior of various materials in this system is presented in Tables II and III, and a detalled discussion is presented in the following pages. In addition to those presented in the tables, certain groups of elements, which may, be troublesome in some situations, should be considered. Ruthenium, rhodium, and osmium are sald to yield a colored solution in the presence of alkali and peroxide (35), but the color is discharged by the addition of ammonium chloride. The following elements are reported to precipitate in an alkaline carbonate medium (48): aluminum(III), beryilium(II), bismuth(III), cadmiam(II), cerium(III), chromium(III), cobalt(II), copper(II), gallium(III), germanium(II), indium(II), indium(III), iron(III), lanthanum(III), lead(II), magnes lum(II), manganese(II), mercury(II), nickel(II), platinum(II), samarium(III), scandium(III), tantalum(V), thorium(IV), titanium(IV), and yttrium(III)。In addition, barium(II), calcium(II), strontium(II), radium(II), dysprosium(III), praseodymium(III), and silver(I) form insoluble compounds with carbonate lon. The specific conditions of given procedure may render some of these either insignificant or more important, and some of them are discussed individually in the following pages.

Bubble evolution - which is accentuated by increased peroxide concentration, the presence of materials which cataylze the peroxide decomposition, or elevated temperatures - may be quite troublesome. Cooling (48) and centrifuging (50) as well as the addition of citrate (61) or phosphate (div) ions have been recommended as methods for reducing this interference.

Magnesium $_{2}$ Calcium $_{2}$ Strontium $_{2}$ and Barium

The maximum amounts of these material which may be present without interference have not been established bot $10 \mathrm{mg}$ of of ther magnesium or strontium does no harm (30). Duse to the relative insolubility of the carbonates of the alkaline earths, interference by precipitation may be observed if the concentrations are sufficiently high $\left(20_{3} 30\right.$, $34,52,64,69)$. Small amounts of magnesium may produce turbidity as 


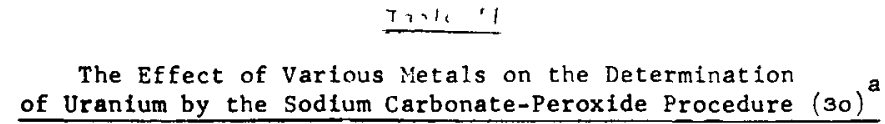

( $10 \mathrm{mg} . \mathrm{U}$ added, $100 \mathrm{ml}$. final volume, measured at $425 \mathrm{m \mu}$ )

\begin{tabular}{|c|c|c|c|}
\hline $\begin{array}{c}\text { Added } \\
\text { Element } \\
\text { "E" } \\
\end{array}$ & $\begin{array}{l}\text { Error due to } \\
10 \mathrm{mg} \text {."E", } \$\end{array}$ & $\begin{array}{l}\text { Maximum "E" } \\
\text { Without } \\
\text { Interference } \\
\text { mg. } \\
\end{array}$ & Reason for Interference \\
\hline $\begin{array}{l}\text { Ag } \\
\text { Au } \\
\text { A1 }\end{array}$ & $\begin{array}{l}\text { Unreadable } \\
+6.0 \\
\text { None }\end{array}$ & $\begin{aligned} &< 0.1 \\
& 5.0 \\
& \ldots\end{aligned}$ & $\begin{array}{l}\text { Precipitate } \\
\text { Reduced to metallic state } \\
\text { May preclpitate }\end{array}$ \\
\hline $\begin{array}{l}\text { As } \\
\text { B } \\
\text { Ba }\end{array}$ & $\begin{array}{l}\text { None } \\
\text { None } \\
\text { None }\end{array}$ & $\begin{array}{l}\cdots \\
\cdots \\
\cdots\end{array}$ & May precipitate \\
\hline $\begin{array}{l}\mathrm{Ca} \\
\mathrm{Ce} \\
\mathrm{Co}\end{array}$ & $\begin{array}{l}\text { Nonec } \\
\text { None }\end{array}$ & $\begin{array}{c}\text { Uncertain } \\
\ldots\end{array}$ & $\begin{array}{l}\text { May precipitate } \\
\text { May form color }\end{array}$ \\
\hline $\begin{array}{l}\text { Cr } \\
\text { Cuc } \\
\text { Fec }\end{array}$ & $\begin{array}{l}+400.0 \\
=40.0 \\
\text { None }\end{array}$ & $\begin{array}{c}<0.1 \\
\text { Traced } \\
\ldots\end{array}$ & $\begin{array}{l}\text { Chromate color } \\
\text { Preclpitate, catalyeis } \\
\text { Precipitate or colloid; } \\
\text { catalyo1s }\end{array}$ \\
\hline $\begin{array}{l}\text { Ge } \\
\text { Hg } \\
\text { In }\end{array}$ & $\begin{array}{l}\text { None } \\
\text { None }\end{array}$ & $\cdots$ & Reduced to metallic state $b$ \\
\hline $\begin{array}{l}148 \\
18\end{array}$ & $\begin{array}{l}\text { None } \\
+3.0 \\
+10.0\end{array}$ & $\begin{array}{l}9 . \dot{c} \\
1.0\end{array}$ & $\begin{array}{l}\text { May precipitate } \\
\text { Precipitate or collold; } \\
\text { catalyois } \\
\text { Color, fades on tending }\end{array}$ \\
\hline $\begin{array}{l}\text { Mb } \\
\text { M1 } \\
\mathbf{P}\end{array}$ & $\begin{array}{l}\text { None } \\
\text { None }\end{array}$ & $\begin{array}{c}8-10^{f} \\
\cdots \\
\cdots\end{array}$ & $\begin{array}{l}\text { Color } \\
\text { May precipitate }\end{array}$ \\
\hline $\begin{array}{l}\mathbf{P b} \\
\mathbf{P d}\end{array}$ & $\begin{array}{l}\text { None } \\
+7.0\end{array}$ & $\ddot{0.0}$ & $\begin{array}{l}\text { Precipitates; may form } \\
\text { color8 }\end{array}$ \\
\hline Pt & None & $\cdots$ & $\begin{array}{l}\text { Precipitates; may form } \\
\text { colorg }\end{array}$ \\
\hline $\begin{array}{l}\text { S1 } \\
\text { Sn } \\
\text { Sr }\end{array}$ & $\begin{array}{l}\text { None } \\
+6.0 \\
\text { None }\end{array}$ & $\ddot{7.0}$ & May precipitate \\
\hline $\begin{array}{l}\text { Th } \\
\text { Ti } \\
\nabla\end{array}$ & $\begin{array}{l}\text { Unreadable } \\
+6.0 \\
+24.0\end{array}$ & $\begin{array}{l}0.5 \\
8.0 \\
1.0\end{array}$ & $\begin{array}{l}\text { Precipitate } \\
\text { Color } \\
\text { Color }\end{array}$ \\
\hline $\begin{array}{l}\mathbf{w} \\
\mathbf{2 n} \\
\mathbf{2 r}\end{array}$ & $\begin{array}{l}\text { None } \\
+3.0\end{array}$ & 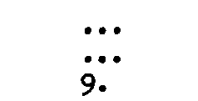 & $\begin{array}{l}\text { Color, fades on standing } \\
\text { Collold }\end{array}$ \\
\hline
\end{tabular}

a. Data 18 taken from or substantiated in Raf. (30) unless otherwise Indicated. For this data, the colutione were bolled, cooled, and filtered prior to color development--see introduction to interference aection for procedure.

b. See Ref. (ss).

c. Behavior 1s complex--see discuselon.

d. See Ref. (6e).

-. See Ref. (oo)

f. Entinated fron Ref. (40).

8. See Ref. (ss). 
Table III

The Effect of Anions, Ammonia, and Other Materials on the Determination of Uranium by the Sodium Carbonate-Peroxide Procedure

\begin{tabular}{|c|c|c|c|}
\hline Materlal & Reference & $\begin{array}{l}\text { No Interference } \\
\text { With, } \mathrm{g} \cdot / 100 \mathrm{ml} \text {. }\end{array}$ & Remarks \\
\hline Acetate & 50 & .... & May increase fading. \\
\hline Ammonia & 30 & Indefinite & $\mathrm{pH}$ effect. \\
\hline Bicarbonate & $58-60$ & $\cdots \cdots$ & pH effect. \\
\hline Chloride as NaCl & 30 & 5.0 & Limit probably mach higher. \\
\hline Fluoride & 47 & $0.01-0.05$ & May produce fading. \\
\hline Hydroxy lamine & 50 & $\cdots \cdots$ & Enhances absorbance. \\
\hline Nitrate as $\mathrm{NaNO}_{3}$ & 30 & 5.0 & Limit is probably much higher. \\
\hline Organic matter & & $\cdots \cdots$ & May give color. \\
\hline Oxalate & 50 & $\cdots \cdots$ & No effect. \\
\hline Perchlorate as $\mathrm{HClO}_{4}$ & 30 & 1.0 & No effect. \\
\hline Peroxide & $2,51,52$, & $\cdots \cdots$ & Commercial $3 \%$ may give color. \\
\hline Phosphate & 47 & 0.1 & Limit probably much higher. \\
\hline Silicate as $\mathrm{SiO}_{2}$ & 47 & 0.06 & May reduce color intensity. \\
\hline Sulfate as $\mathrm{Na}_{2} \mathrm{SO}_{4}$ & 30 & 5.0 & Limit is probably much higher. \\
\hline Tartrate & & .... & May reduce color intensity. \\
\hline
\end{tabular}


a result of the hydrogen formation (68). The precipitates may be removed by filtration $(52,69)$ with the usual precautions to prevent occlusion and/or entrainment of uranium. The alkaline-earth salts of the uranyl carbonate complex, such as $\mathrm{Ba}_{2} \mathrm{UO}_{2}\left(\mathrm{CO}_{3}\right)_{3}$, are quite insoluble $(25,52)$; but in the presence of excess carbonate they are unstable, with respect to the formation of the alkaline-earth carbonates and the uranyl-tricarbonate complex (7). However, entrainment of these or similar salts presumably may occur if a bulk of preclpitate is obtained, and the solution should not be filtered until after the peroxide is added. Addition of the peroxide even before the solution is rendered alkaline is preferable. Elimination of the calcium interference by precipitation as the oxalate (88) or by the formation of the colorless tartrate complex (64) has been proposed.

\section{Aluminum}

Aluminum does not interfere in the usual determination $(30,47)$, but a bulk of the metal or a low pH may produce preclpitation. Removal of the precipitate will not vold the solution of aluminum and most certainly will yleld low results due to entrainment of uranium (15).

$\underline{\text { Titanium }}$

While titanium normally is precipitated in an alkaline solution $(15,20$, $47)$, the presence of peroxide, contrary to some reports $(35,47)$, results in the formation of a soluble colored species. The color thus formed is much less intense than the corresponding color in an acidic solution (40), but is sufficient to produce a positive $6 \%$ error for the determination of $10 \mathrm{mg}$. of uranium in the presence of $10 \mathrm{mg}$. of titanium (30). A maximum of $8.0 \mathrm{mg}$. can be tolerated if an error of 1 ess than one percent is to be maintained (30). An easy check for the presence of titanium is to add the peroxide before making the solution alkaline and observing to see if the characteristic titanium-peroxide color is developed.

Vanadium

Although early reports indicated that vanadium and hydrogen peroxide reacted to give a color only in an acidic solution $(22,35)$, it has been established that this element also must be considered as a serious color interference in a basic solution $(5,8,20,24,30,34,36,47,31,52,56$, 65). A comparison of the spectral transmittance curves of vanadium and uranium, Figure 4 (30), indlcates interference over the useable wavelength range. Although the molar absorbtivity of the uranium complex is much greater than that of the vanadium, the absorbtivities on a welght basis are much more similar and at wavelengths shorter than $385 \mathrm{~m} \mu$ vanadium is the higher of the two. At longer wavelengths the interference becomes less pronounced. Huston (30) found that a maximum of $1.0 \mathrm{mg}$. could be tolerated if the error in measuring $10 \mathrm{mg}$. of urarium at $425 \mathrm{~m} \mu$ was to be 1 ess than one percent. 
Raisen-Streden $(47,68)$ determined the vanadium present and corrected the absorbance values obtained for uranium solution, but this has produced erratic results when attempted by other invesigators (34, $51,52)$. The erratic behavior has been attributed to the high temperature-dependence of the vanadium color $(34,52)$. Separation of uranium from vanadium by ethyl ether extraction has not been satisfactory $(24,51)$, but extraction with penta-ether after reduction with tartaric acid has been more successful. Vanadium has been found to accompany uranium to a marked extent in alkaline precipitations (51), but coprecipitation of aluminum and uranium as phosphates has been used for the separation $(15,16)$. Eliminacion of the vanadium interference, for the most part, has been accomplished by special treatment in the sodium hydroxide system.

The need for concern about vanadium interference may be determined by the addition of peroxide prior to making the solution alkaline and observing if the characteristic vanadium-peroxide color is developed.

\section{Chromium}

Chromium is generally considered as the most serlous interference in this and the other alkaline systems $(11,30,34,35,43,45,47,50,51,52,56$, 68) because of the relatively high absorbance of the chromate lon. If chromium is present, it will be found in the chromate form because of the oxidizing power of the alkaline-peroxide system. Figure 4 shows a comparison of the spectral transmittance curves for chromium and uranium and from these curves it may be shown that on a weight basis chromium has a higher absorbtivity than uranium over the entire vseful wavelength range. Huston (30) found that at $425 \mathrm{m \mu} 0.1 \mathrm{mg}$. produced no interference in the measurement of $10 \mathrm{mg}$. of uranium but $10 \mathrm{mg}$. of chromium gave a positive error of $400 \%$. The error would be larger at shorter wavelengths. Sample blanks, containing all reagents but the peroxide, have been used to eliminate the interference $(47,56)$, but the reliability is questionable since similar techniques have been reported unsatisfactory $(51,52)$.

Chromium and uranium have been separated by: (a) electrolysis with a mercury cathode (51); (b) precipitation of the chromium in the presence of carbonate (15); (c) a single ammonium hydroxide precipitation, dissolution in nitric acid, and extraction of the uranium with ethyl ether (51); oxidation of the chromium to chromate followed by a precipitation of the chromium with barium ion (50), or a double precipitation of the uranium with ammonium hydroxide $(51,69)$. Chromium has been reported to be the only serfous color interference which is appreciably extracted by penta-ether.

\section{Manganese}

The interference of manganese may be due to colloid formation (11) and/or catalysis of peroxide decomposition ( 34 ). The interference is erratic and the small amount carried through an extraction procedure 
may cause trouble (11). Coagulation helps to reduce the error caused by a collodial dispersion of manganic hydroxide, which occasionally has been characterized as a colored complex. In the measurement of $10 \mathrm{mg}$. of uranium at $425 \mathrm{m \mu}$, Huston (30) reported that $10 \mathrm{mg}$. of manganese gave a positive $3 \%$ error while $9 \mathrm{mg}$. did not interfere in the procedure involving an alkaline carbonate preclpitation. The erratic effect of manganese suggests that the data may not be repeatable and, furthermore, negative errors could be produced by entrainment of uranium in the precipitate.

Iron, Cobalt, and Nickel

The fact that these elements will precipitate in an alkaline medium gives rise to both interference and a frequently used means of separation $(11,20,30,34,35,47,50,52,64,69)$. Huston (30) reported that $10 \mathrm{mg}$. of iron, cobalt, or nlckel produced no error in the measurement of $10 \mathrm{mg}$. of uranium at $425 \mathrm{m \mu}$ after a carbonate separation. The likely entrainment of uranium in the precipitate, however, makes solvent extraction a more attractive means of separation. Small amounts of iron may form a colored colloldal suspension to give high results $(10,11,35$, 50) or it may catalyze the peroxide decomposition to cause fading of the uranium peroxide color and/or troublesome bubble evolution. Because of the varled form of the interference, the use of a sample blank to correct for small amounts of Iron (47) is of limited application and dependabllity. Tartrate ion has been used to complex the iron before extraction (11) or before color development when the absorbance is measured at wavelengths longer than $400 \mathrm{~m} \mu(20,64)$.

\section{Copper}

The bulk of the copper present is precipitated in the medium used for uranium measurement $(20,34,47,52,69)$. The remaining amount may do no harm (47) or it may catalyze decomposition of the peroxide $(30,48,62)$ to produce low results. Smalles and Furby (62) found sufficlent copper to produce the catalytic effect in distilled water from stills using copper colls. When using this water, the absorbance of the uraniumperoxide solution was observed to increase gradually over a ten-minute period and then fade rapidly. The catalytic effect may be quite dependent on the nature of the particular solution and it may lower the no-interference 1 imit much below the $0.2 \mathrm{mg}$. per $100 \mathrm{m1}$. established by Huston (30). A negative $40 \%$ error reported for a sample containing $10 \mathrm{mg}$. each of uranium and copper (30) appears to indicate the magnitude of uranium that may be entrained in the alkaline precipitate.

\section{Silver and Gold}

Silver is precipitated in a basic carbonate solution and the concentration limit without interference in the measurement of $10 \mathrm{mg}$. of uranium has been set at less than $0.1 \mathrm{mg}$. (39). 
Gold is said to be reduced to the metallic state under the conditions used in the uranium analysis (35). Five mg. of gold has been reported to give no interference but $10 \mathrm{mg}$. produced a positive $6 \%$ error in the measurement of $10 \mathrm{mg}$. of uranium (30).

\section{Zircontum}

Huston ( 30 ) found a positive $3 \%$ error in the measurement of $10 \mathrm{mg}$. of urantum in the presence of an equal amount of zirconium. The observed interference $(17,30)$ evidently is due to the formation of either colloidal zirconium hydroxide (17) or an insoluble zirconium peroxide salt (46). The insoluble materlal has a strong tendency to absorb uranium and filterIng or centrifuging is very likely to produce low answers. The best means of eliminating this interference is to use the sodium hydroxide system since the preclpitate does not form at a high $\mathrm{pH}$.

\section{Molybdenum and Tungsten}

Contrary to the data of Hackl (22), both elements produce a weak yellow color in the carbonate-peroxide medium $(21,24,30,47,58)$, which interferes with the uranium determination. Comparative absorbance spectra are not avallable for the carbonate-peroxide system but the uranium forms a much stronger color than efther the molybdenum or tungsten (56). Both tungsten $(47)$ and molybdenum $(11,47)$ colors fade rapid1y and the interference is eliminated, for small amounts, by allowing the solutions to stand. The color due to $10 \mathrm{mg}$. of molybdenum fades completely in onehalf hour but produces a $10 \%$ error in the measurement of $10 \mathrm{mg}$. of uranium if the waiting period is omitted (30). If the molybdenum concentration is extremely high, a separation must be made. Solvent extraction usually is satisfactory although slight interference has been observed after an ethyl ether extraction (24). In TBP (tri-nbutyl phosphate) and similar solvents some molybdenum may enter the organic phase but little or more will accompany the uranium on re-extraction.

Cerium

Huston (30) observed no interference and Raisen-Streden (47) concurred that in the usual sample, cerium is no problem because it is co-precipitated with iron. Other Investigators, however, have reported that both cerium(III) and cerium(IV) may produce a strong yellow color in this procedure (56). The conflicting information is reasonable because of the complexity of the reactions that are possible. Cerium(III) may be oxidized under these conditions, but the oxidation may yield strongly colored cerfum(III)-cerium(IV) compounds as well as various other colored groups containing cerfum(IV). Since the products are varied and difficult to reproduce, the interference is erratic.

The bulk of cerium is precipitated by bolling in a carbonate solution, but a sufficient amount remains in solution to considerably enhance the uranium-peroxide color if the conditions are right. An oxalate 
separation, after reduction to cerium(III), has been recommended for cerlum concentrations as low as $0.02 \mathrm{mg}$. per ml. (50). If a bulk of cerium is separated in this manner, there is a tendency for uranium to be occluded.

Thorium

Thorium is precipitated in an alkaline medium and may be removed by filtration, but a loss of uranium is probable. Guest and Zimmerman (21) applied the alkaline-peroxide separation satisfactorily by re-precipitating the thorium at least once, and twice if the preclpitate was large.

Ammonia

It appears that ammonia affects this system only in terms of 1 ts influence on the $\mathrm{pH}$, and a more complete discussion is presented in the section pertaining to the $\mathrm{pH}$ effects.

Acetate, Tartrate, and Oxalate

Oxalate has no effect on the system but acetate may cause noticeable fading of the color if the solution is allowed to stand longer than five minutes after the color is developed (50). Tartrate has not been mentioned for this specific system, but it is said to reduce the color intensity in an ammonium hydroxide medium (64). Whether the tartrate decreases the absorbance by lowering the $\mathrm{pH}$ or complexing the uranium is not clear. Uranyl tartrate complexes have been reported $(13,14)$ but the relative stabilities of these and the peroxide complexes are not available.

\section{Bicarbonate}

Bicarbonate, which is formed directly in the solution if sodium carbonate is used for the neutralization, can be a serious interference because of its influence on the $\mathrm{pH}$ and/or its spectral absorbance. The low results reported by Scott for solutions containing bicarbonate when the measurement was made at $360 \mathrm{m \mu}(58,59$, 60) were apparently due to a decreased $\mathrm{pH}$. As previously discussed under the "Effect of $\mathrm{pH}$," the absorbance varies directly with the $\mathrm{pH}$ up to the maximum obtainable in this system, about 11. In contrast to the low results of Scott, high results may be obtained at the $360 \mathrm{m \mu}$ wavelength unless proper blanks are used because of the spectral absorbance of the blcarbonate lon. The latter effect decreases with increasing wavelengths and becomes insignificant in the vicinity of $400 \mathrm{~m} \mu$.

Chloride, Nitrate, and Sulfate

Smales (61) has reported that the addition of these anions as ammonium salts has no effect on the determination of uranium. Huston (30) 
confirmed the indifference of the system to the anions themselves but found a definite effect, due to $\mathrm{pH}$ variations, when ammonium salts were used. The $\mathrm{pH}$ variation presumably was responsible for the observation of Roberts and Seath (5o) that the system is sensitive to small amounts of nitrate, added as ammonium nitrate. In Huston's (30) study with sodium salts, $5 \mathrm{~g}$. of the sulfate, nitrate, or chloride had no effect, and the limit probably is much higher.

\section{Fluorides}

Small amounts of fluoride do not harm but large amounts may exert a bleaching action on the uranium-peroxide color $(22,47,56)$. RaisenStreden found that up to $10 \mathrm{mg}$. of fluoride per $100 \mathrm{~m} 1$. had no effect, from 10-50 mg. per $100 \mathrm{ml}$. produced slight bleaching, and larger amounts caused rapid fading (47).

Hydrogen Peroxide, Dilute

It has been reported that the commercial dilute hydrogen peroxide ( $3 \%$ ) may give a yellow color when treated with an alkali $(2,51,52)$. This difficulty has not been encountered with the $30 \%$ peroxide.

Hydroxylamine

Hydroxylamine produces increased spectral absorbance, apparently because of the formation of a hydroxylamine uranate species, and must be removed from the sample. The removal may be accomplished by bolling with potassium bromate in the presence of nitric actd (50).

Organic Material

The presence of organic matter in an alkaline solution may produce a color when hydrogen peroxide is added $(5,11,34,35,51,52,62)$. This has been observed especially after an ethyl ether $(5,34,51,52)$ or pentaether (21) extraction. A perchloric acid or similar treatment may be applied after the extraction to burn out the organic matter $(21,34,51$, $52,62)$. Alternatively, carbon tetrachloride or chloroform may be used to extract the organic materials from an aqueous IM nitric acid solution (48). Analysis of the carbon tetrachloride and chloroform phases have shown that only trace amounts of uranium are extracted.

The sertousness of the interference of organic material is dependent on the amount and source of the material present. If the interference is due to decomposition products of the extractant, a simple blank correction may be adequate. If the organic originates in the sample and is carried through an extraction procedure, the use of a slightly acidic stripping solution may prevent the re-extraction (68).

Perchlorates

Perchlorates are important because of the use of perchloric acid in 
the removal of organic matter. In the only report on the sub fect, Huston (30) concluded that no interference would be encountered but the maximum amount tested was $1 \mathrm{ml}$. of the concentrated acid.

\section{Phosphates}

The addition of phosphate to decrease bubble formation $(47,66)$ has been recommended, but the amount which can be safely tolerated is uncertain. The reported concentration limit without interference has ranged from about $70 \mathrm{mg} .(47,56)$ to over $1000 \mathrm{mg}$. (61) in $50 \mathrm{ml}$. of solution. Excessive amounts of phosphate diminish the color of the uranium-peroxide solution but the observations usually have been clouded by the use of ammonium salts. An ammonium salt would be expected to diminish the color by lowering the alkalinity unless the $\mathrm{pH}$ is controlled. If the $\mathrm{pH}$ is controlled it seems $1 \mathrm{fkely}$ that the concentration limit is sufficlently high to be of little or no concern for the usual sample.

\section{Silicates}

Large amounts of silicates cause bleaching of the uranium-peroxide color $(22,47,58)$, but Raisen-Streden (47) found that up to $60 \mathrm{mg}$. of $\mathrm{S}_{2} \mathrm{O}_{2}$ per $100 \mathrm{ml}$ could be tolerated.

\section{Stability}

The stability of the peroxide color is dependent on several factors. Investigators have reported that fading of the uranium-peroxide color in this system is not appreciable within thirty minutes to one hour. Raisen-Streden (47) reported that in pure solutions the color intensity was unchanged after two minutes of boiling or two hours of standing at room temperature. The following conditions result in an increased fading rate: higher temperature (49), insufficient (50) or excess (30) hydrogen peroxide, increased sodium carbonate concentration, and the presence of materials which catalyze the decomposition of the hydrogen peroxide or the uranium-peroxide species. In the usual procedures only the last of these is highly important, and the materials causing such an effect are discussed in the interference section. Otherwise, the stability of the color does not present a problem in this method. Once the uranium-peroxide color has faded, however, the addition of more peroxide may not fully restore the color intensity (44).

Sensitivity, Accuracy, and Precision

\section{Sensitivity}

Most reported sensitivity data have been confined to statements such as...not very sensitive. Specific values that have been reported are confused by the various instruments, conditions, and definitions that have been used in this work.

From the percent transmittance-concentration curves reported by 
Huston (30), Figure 5, the following sensitivity values have been calculated for the Coleman Model 11 spectrophotometer with 19-mm. OD (approximately 16-mm。 ID) cylindrical cells, and the Beckman Model DU spectrophotometer with $1-\mathrm{cm}$. cells. With the Coleman instrument a uranium concentration of approximately $27 \mathrm{\mu g} . / \mathrm{ml}$. was required to produce a spectral absorbance value of 0.100 . With the Beckman instrument, adjusted to give. a slit width of $0.04 \mathrm{~mm}$, a corresponding uranium concentration of $37 \mu \mathrm{g}_{\circ} / \mathrm{ml}$. was required. Procedural details used by Huston, discussed in the introduction to "Interferences," included color development at a pH of 9.9-10.4 and measurement at $425 \mathrm{m \mu}$ against a water blank.

It should be noted that the sensitivity is $\mathrm{pH}$ dependent and increases greatly with decreased wavelength (45). Measurements at $370 \mathrm{m \mu}$ are said to be about eight times as sensitive as those obtained at $425 \mathrm{m \mu}$ (34), but the reagent concentration must be closely controlled and appropriate blanks used.

\section{Accuracy}

When the measurements are made at $370 \mathrm{m \mu}(34)$ or $400 \mathrm{~m} \mu$ (49), after separation steps have been employed, it has been reported that the relative degree of accuracy is within $\pm 3 \%$. When the measurements are made on pure solutions, $a \pm 1 \%$ has been reported (49). Both of the above values apply for solutions adjusted to a $\mathrm{pH}$ of 11 or higher. For a series of pure solutions containing various amounts of uranium and having a $\mathrm{pH}$ of 9.9 to 10.4 , Huston (30) obtained a relative average error of $0.2 \%$ and $2.0 \%$ for the Beckman Model DU with $1-\mathrm{cm}$. cells and the Coleman Model 11 with 19-mm. OD cylindrical cells, respectively, at $425 \mathrm{m \mu}$. The use of $5-\mathrm{cm}$. cells has been reported to give improved accuracy compared to smaller cells because the change in light path due to the presence of oxygen bubbles on the walls of the cell is less significant (47).

\section{Precision}

The precision of this method on pure solutions has been reported to be within the experimental error of the photometric measurements (45). It would be possible to increase the precision for higher uranium concentrations by application of differential colorimetry techniques (27, $28,38,39)$.

\section{SODIUM CARBONATE-HYDROXIDE-PEROXIDE METHOD}

The combination of sodium hydroxide and sodium carbonate as the alkaline agents in the peroxide uranium determination has evolved from the sodium carbonate system. The modification by the addition of sodium hydroxide, in general, was introduced for one of two reasons: (a) to eliminate the formation of bicarbonate by neutralization of the acidic solution with sodium hydroxide ( 58,59 , 60,63 ); and, (b) to eliminate the $\mathrm{pH}$ effect on the color intensity by adding the strong base to consistently produce a $\mathrm{pH}$ of 11 or higher $(45,49,51,52$, 
$62,63,89)$. Actually, the former reason could be considered as a pH effect, but it is listed separately because investigators concerned with the presence of bicarbonate used a different mode of attack in their work.

The supporters of the bicarbonate-as-am-interference theory used sodium hydroxide to neutralize the acidic solution and then added sodium carbonate to supply the alkaline medium. The net result is the same as that obtained in the sodium carbonate method except that the elimination of a possible bicarbonate buffering effect yields aigher and better controlled pH and a resultant increase in sensitivity and precision. Furthermore, the addition of the carbonate to a meutral solution makes possible the use of a specific amount of the reagent. This is definite advantage if measurements are made at wavelengths shorter than $400 \mathrm{m \mu}$ because of the absorbance of the reagent. These facts emphasize that the preliminary neutralization with sodium hydroxide is desirable but, otherwise, the behavior and characteristics of the system are no different than those discussed for sodium carbonate system. The remainder of this section, therefore, is devored to the combined system where sodium hydroxide is used to provide medium of higher alkalinity than that obtained with sodium carbonate alone.

Since the spectral absorbance of a given uranium-peroxide concentration is $\mathrm{pH}-$ dependent below a $\mathrm{pH}$ of about 11 , the addition of sodium hydroxide was $a$ logical modification of the method. Although the alkalinity can be adjusted with sodium hydroxide lone, many investigators chose to include sodium carbonate either as a carry-over from the established sodium carbonate method or because of the frequency with which carbonate separations are performed. It also has been stated that when elements which precipitate in alkaline media are present, less occlusion of uranium occurs if sodium carbonate is died (44). When a solution blank is needed because of colored impurties in the alkaline medium, sodium carbonate must be used to prevent the precipitation of uranium. Aside from the use of a biank, it seems to make no difference whether or not carbonate is present if the $\mathrm{pH}$ is 11 , or higher, and the megsurements are made at $400 \mathrm{~m} \mu$ with an instrument providing a narrow band width. Likewise, the sodium hydroxide concentration is not critical if sufficient amount to give a $\mathrm{pH}$ of 11.5 , or higher, is used. At other wavelengths, the pH effect is not as well defined, and the data re less complere. It 1 s certain that at wavelengths not in the vicinity of $400 \mathrm{m \mu}$ the ph is important, but the effects of carbonate and other variable are not too elear. For these and other reasons, to be discussed later, $400 \mathrm{m \mu} 18$ recomended for routine andysis. At this wavelength the hydrogen peroxide concentration not critical, but $1 \mathrm{ml}$ of the $30 \%$ reagent per $100 \mathrm{ml}$. of solution appears to be the optimum amount.

\section{Absorption Spectra}

Qualitatively, the absorption spectra for this system are much the same as those reported for the sodium earbonate system. The spectra of both the colored uranium solution and the reagents, as presented by Orlemar, et al. (45), are compared to a pseudo spectrum for the uranium species in Figure $\sigma_{0}$ The pseudo spectrum was obtained by subtracting the absorbance of the reagents from the absorbance of the solution containing the uranium-peroxide complex and indicates the false maximum at $340 \mathrm{m \mu}$ that has been reported elsewhere (52). 
To obtain the true spectrum of the uranium-peroxide species, the amount of the reagents consumed in the reaction must be considered. Such a correction has been applied to spectral transmittance data by Rider, et al. (49), and is shown in Figure 7. From this figure it is apparent that there is no point of minimum transmittance, or maximum absorbance, in the range of 320-600 $\mathrm{m \mu}$. Figures 6 and 7 show that the absorbance by the reagents becomes important at wavelengths shorter than $400 \mathrm{m \mu}$. As in the other alkaline systems, a precise selection of the wavelength is necessary because of the variation of absorbance with wavelength. The wavelength of $400 \mathrm{m \mu}$ is perhaps the most desirable since it represents a compromise between sensitivity and reagent interference. Also, as discussed later, the $\mathrm{pH}$ of the system is not as critical at $400 \mathrm{m \mu}$ as it is at other wavelengths.

Beer's law appears to be obeyed over the entire useful wavelength range if a band width of $35 \mathrm{m \mu}$ or less is used (20). Specifically, Iinear variation of absorbance with uranium concentration has been reported for $360,370,380,390$, and $400 \mathrm{m \mu}$ by Orleman, et a1. (45), and at $438 \mathrm{m \mu}$ by Smales, et a1. (62). At $400 \mathrm{m \mu}$ the linear relationship holds up to a concentration of at least $20 \mathrm{mg}$. per $100 \mathrm{ml}$. when a Beckman DU spectrophotometer providing a narrow band width and $1-\mathrm{cm}$. cells are used $(45,48)$. At wavelengths shorter than $400 \mathrm{m \mu}$ the reagent concentrations must be carefully controlled in order to obtain a linear absorbance-concentration relationship.

\section{Effect of Reagent Concentration}

The reagent concentration is much less critical in this method than in the one using sodium carbonate alone. This is primarily due to the more or less standardized practice of using a wavelength of $400 \mathrm{~m} \mu$ for the absorbance measurements and adding a sufficient ambant of sodium hydroxide to give a $\mathrm{pH}$ of 11 or higher. The use of $400 \mathrm{m \mu}$ is fortunate in that neither the $\mathrm{pH}$, above a lower limit of about 11.5, nor the concentration of the sodium carbonate have an effect on the absorbance at this wavelength. In fact, the presence or absence of carbonate apparently makes no difference at $400 \mathrm{~m} \mu$. Since the $\mathrm{pH}$ is not critical, the concentration of sodium hydroxide is not important except to obtain the minimum $\mathrm{pH}$. At other wavelengths, the system is not so we11 behaved.

The peroxide concentration may vary over a wide range from the minimum amount necessary to develop full color up to an amount which produces excessive gas evolution. In general, a range of 0.5 to $10 \mathrm{ml}$. of $30 \%$ hydrogen peroxide per $100 \mathrm{ml}$. of solution can be tolerated, but $1 \mathrm{ml}$. appears to be the optimum amount. At wavelengths shorter than $400 \mathrm{m \mu}$, a consistent amount must be used.

\section{Sodium Carbonate}

The presence of sodium carbonate has practically no effect on the uranium peroxide color at $400 \mathrm{~m} \mu$ as long as its presence does not lower the $\mathrm{pH}$ below $11(44,45,48)$. The Independence of absorbance at $400 \mathrm{m \mu}$ with respect to the alkaline agent and the $\mathrm{pH}$ is shown in Figure 8 by combination of data presented by Rider, et al. (48), converted from percent transmittance to absorbance, and Orleman, et al. (45). The data may seem to indicate that the type of alkaline 
agent is more important than the $\mathrm{pH}$ at wavelengths other than $400 \mathrm{~m} \mu$. But, in consideration of data that is specific to the sodium hydroxide system and the apparent precision of the $\mathrm{pH}$ applying to the above data, I belleve the sole cause of variation in absorbance of the uraniumperoxide species is $\mathrm{pH}$. The total absorbance of a solution containing the spectes, of course, will depend on reagent concentration if the measurement is in the region of $350 \mathrm{m \mu}$.

In addition to its use as an alkaline reagent, sodium carbonate has been added to effect a carbonate separation (45) or to hold uranium in solution in an alkaline medium prior to the peroxide addition (44). When used to produce specific results such as these the sodiumcarbonate concentration may become quite Important and must be evaluated according to the function it is to perform.

\section{Sodium Hydroxide}

The effect of this reagent is purely one of $\mathrm{pH}$ control. When measurements are made at $400 \mathrm{m \mu}$, an excess of this reagent will do no harm and the procedure can be standardized by adding an amount that will always produce a pH of 11.5 or higher. At other wavelengths, the $\mathrm{pH}$ is important even in highly alkaline solutions, as discussed in the previous subsection. At wavelengths shorter than $400 \mathrm{m \mu}$, the absorbance of the reagent may be appreciable.

\section{Hydrogen Peroxide}

At a wavelength of $400 \mathrm{m \mu}$ or longex, the hydrogen peroxide concentration does not effect the absorbance unless an extreme amount in either direction is used. An insufficient amount will produce incomplete color development and an excessive amount will cause troublesome bubble evolution. At wavelengths in the vicinity of $320 \mathrm{m \mu}$, the absorbance of the peroxide itself is significant (See Figure 2) and requires standardization of the amount or use of appropriate blanks for the measurement. At any wavelength, 0.5 to $10 \mathrm{ml}$. of $30 \%$ hydrogen peroxide per $100 \mathrm{ml}$. of solution is satisfactory but $1 \mathrm{~m} 1$. seems to be the optimum amount $(45,48)$.

\section{Effect of $\mathrm{pH}$}

The pH effect in this, as in the sodium carbonate system, is rather complex. A number of reports contain data pertaining to this effect $(20,44,45,49,62)$, but much of it is concerned only with the behavior at $400 \mathrm{m \mu}$. The combined data of Rider, et al. (49) and Orleman, et al. (45) presented in Figure 8 gives the best picture of general spectral behavior available. As previously discussed in connection with the sodium carbonate concentration, all of the variation shown is belleved to be due to the $\mathrm{pH}$ effect. That is, a change in $\mathrm{pH}$ occasions a change in the nature or characteristics of the absorbing species and produces an isosbestic point at, or very near, $400 \mathrm{m \mu}$.

The presence of the isosbestic point makes $400 \mathrm{m \mu}$ the Ideal wavelength to use for the determination of uranium in this medium. Below a pH of about 11.5 the 
1sosbestic point is non-existant and the absorbance at $400 \mathrm{m \mu}$ becomes $\mathrm{pH}$ dependent $(20,44,45,62)$, as shown in Figure 9 (48). It is important to note that the degree of non-dependence on the $\mathrm{pH}$, even at values above 11.5, w111 be dependent on the spectral purity of the radiation. In this respect, it is desirable to use a narrow band width and to check the accuracy of the wavelength scale and/or the location of the isobestic point on the instrument to be used.

\section{Inter ferences}

The investigation of interferences in this system is far less complete than that for the carbonate system. However, since carbonate is present in both methods and the only altered factor is the $\mathrm{pH}$, the information presented for the sodium carbonate system may be used to supplement the following discussion. All interference data in this section pertains to the use of $400 \mathrm{m \mu}$.

From the data which are presented in this section, Table IV has been compiled to present a list of the materials which have been investigated for interference in this system. The approximate errors and maximum tolerable amounts are based on meager information and should be accepted only as very rough approximations. In some cases procedural and other detalls are important and the text should be consulted before applying the summary ilsting to speciflc cases.

As a supplement to Table IV and the following discussion several elements have been cited as possible interferences due to their characteristic behavior (40): elements precipitated in an alkaline medium are beryllium(II), bismuth(III), cadmium(II), cerium(III), gallium(III), germanium(II), Indium(II), indium(III), lanthanum(III), magnesium(II), mercury(II), platinum(II) samarium(III), scandium(III), tantalum(V), thorium(IV), titanium(IV), and yttrium(III):, elements precipitated by the carbonate ion are barium(II), calcium(II), dysprosium(III), praseodymium(III), radium(II), silver(I), and strontium(II); and elements complexed to produce a colored species in an alkaline-peroxide medium are cerium, nfobium, titanium, and vanadium.

Aluminum, Lead, and Zinc

These elements form precipitates in a slightly alkaline solution but dissolve when an excess of sodium hydroxide is added. However, an addition of hydrogen peroxide to the strongly alkaline solution produces a precipitate which will not completely dissolve on the addition of more sodium hydroxide $(44,45)$. If this precipitate is removed by filtration, a loss of uranium by occlusion results (44). A change in the order of reagent addition to peroxide, carbonate, and then sodium hydroxide reduces the likelthood of occlusion over and above the reduced tendency to precipitate (45). This approach was used to obtain the data which indicate that more than $50 \mathrm{mg}$. of aluminum can be tolerated while lead and zinc start to interfere in the range of $20-50 \mathrm{mg}$. per $100 \mathrm{ml}$. 
Table IV. Summary of the Effect of Various Materials on the Determination of Uranium by the Sodium Carbonate-Sodium Hydroxide-Peroxide Procedure ${ }^{a}$

\section{Material}

Acetate
Chloride
Fluoride
Nitrate
Organic Material
Phosphate
Perchlorate
Sulfate
Al
Co
Cr
Cu
Fe $^{b}$

Mn

Moc

Ni

$\mathbf{P b}$

$\mathrm{Zn}$
Approximate Amount of Interference by the Given Amount of Material

None $\quad \begin{aligned} & \text { None at } 50 \mathrm{~g} \cdot / 1 \\ & -2 \% \text { at } 30 \mathrm{~g} \cdot / 1 \\ & \text { None at } 10 \mathrm{~g} \cdot / 1 \\ & -2 \% \text { at } 30 \mathrm{~g} \cdot / 1 \\ & +3 \% \text { at } 10 \mathrm{~g} \cdot / 1 \\ & \text { None at } 50 \mathrm{~g} \cdot / 1 \\ & +3 \% \text { at } 30 \mathrm{~g} \cdot / 1 \\ & \text { None at } 0.5 \mathrm{~g} \cdot / 1 \\ & +3 \% \text { at } 10-4 \mathrm{~g} \cdot / 1 \\ & +6 \% \text { at } 0.2 \mathrm{~g} \cdot / 1 \\ & +3 \% \text { at } 0.2 \mathrm{~g} \cdot / 1 \\ & -2 \% \text { at } 0.5 \mathrm{~g} \cdot / 1 \\ & \text { Erratic } \\ & \text { None at } 0.5 \mathrm{~g} \cdot / 1 \\ & -6 \% \text { at } 0.5 \mathrm{~g} \cdot / 1 \\ & -10 \% \text { at } 0.5 \mathrm{~g} \cdot / 1 \\ & -2 \% \text { at } 0.5 \mathrm{~g} \cdot / 1\end{aligned}$

Approximate Maximum

Concentration Without Interference

$$
\begin{aligned}
& 50 \mathrm{~g} \cdot / 1 \\
& 10-30 \mathrm{~g} \cdot / 1 \\
& 10-30 \mathrm{~g} \cdot / 1 \\
& 10-30 \mathrm{~g} \cdot / 1
\end{aligned}
$$

Best to remove completely

$$
\begin{array}{r}
10 \mathrm{~g} \cdot / 1 \\
>50 \mathrm{~g} \cdot / 1 \\
10-30 \mathrm{~g} \cdot / 1 \\
0.5 \mathrm{~g} . / 1
\end{array}
$$

Undetermined

Order of $0.1 \mathrm{mg} . / 1$.

$0.1 \mathrm{~g} . / 1$.

$<0.28 \cdot / 1$.

Any amount may be troublesome

$$
\begin{aligned}
& >0.5 \mathrm{~g} \cdot / 1 \text {. } \\
& 0.2-0.5 \mathrm{~g} \cdot / 1 \text {. } \\
& 0.2 \mathrm{~g} \cdot / 11 \\
& 0.2 \mathrm{~g} \cdot / 1
\end{aligned}
$$

${ }^{\text {A } 11}$ approximations are based on analysis of solutions containing

$5 \mathrm{mg}$. of $\mathrm{U} / 100 \mathrm{ml}$. unless otherwise noted.

betermination made on solution containing $10 \mathrm{mg}$. of $\mathrm{U}$.

csolution stood 2 hours prior to absorbance measurement. 
Chromium

As in the carbonate system, chromium is the most serious interference $(2,43,44,49)$. Its behavior is much the same in both systems, and a complete discussion will not be repeated here. Again, the spectral absorbance of the chromate species (see Pigure 4 ) is the source of trouble, and chromium must be virtually absent to avold interference (45). A double ammonia precipitation of the uranium after the chromium has been oxidized to chromium(VI) is an effective means of separation. The oxidation may be performed by ammonium persulfate, perchloric acid, or potassium bromate $(44,45)$. Removal can also be accomplished by electrolysis from a sulfuric acid solution, using a mercury cathode.

\section{Manganese}

The manganese interference results from a combination of occlusion of uranium by the precipitated manganic hydroxide, spectral absorbance by a colloidal suspension, and/or catalysis of peroxide decomposition $(44,45)$. This combination of effects may produce errors that are large or small, positive or negative, and not directly related to the manganese concentration $(44,45)$. Errors may persist evers when the solutions are digested and filtered before measurement. Apparently, the concentration of manganese must be virtually nil to eliminate all interference. Electrolysis and carbonate or ammonia precipitation have been used to separate the manganese $(44,45)$. Electrolysis may be the best of the methods cited, but none of them appear to be highly successful (44).

Iron, Cobalt, and Nickel

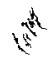

These elements precipitate in a basic medium and the precipitates interfere with absorbance measurements $(10,20,44,45,49)$. If the precipitates are removed, appreciable uranium may be lost by occlusion. Carbonate separations have been used but, if the concentration of interfering material is large, a reprecipitation with thorough washing is necessary $(4,45)$. A clean separation is particularly difficult in the case of high nickel concentration, but reported data indicate that for no interference the maximum allowable amount for either iron or nickel is about $20 \mathrm{mg}$. per $100 \mathrm{ml}$. (45). Presumably cobalt would behave similarly. Repeated separations should increase the limits considerably, and the addition of peroxide prior to the addition of carbonate may aid in this direction also. If the precipitate is very small or is not properly coagulated, an interfering colloldal suspension may be formed. Iron has also been reported to interfere by catalyzing the decomposition of the peroxide $(4 \theta)$.

\section{Copper}

The copper color interferes to produce a positive error if a sufficiently large amount is present (45). It is generally easy to reduce 
the copper concentration to a level where the color does not interfere, approximately $100 \mathrm{mg}$. per 1 ., by an ammonia separation $(20,45)$. Copper has been reported to catalyze the decomposition of peroxides in this system (20), especially in the presence of Iron salts (48), but definitive data is not available. Presumably, this effect could vary considerably depending on the exact nature of the solution.

\section{Molybdenum}

In the presence of alkaline peroxide, molybdenum forms a colored solution which interferes with the uranfum determination $(44,45,49)$. The intensity of the color depends on both the molybdenum and the peroxide concentration but fades completely on standing for two hours when the usual $1 \mathrm{ml}$. of $30 \%$ hydrogen peroxide $1 \mathrm{~s}$ used. It $1 \mathrm{~s}$ evident from Table $\nabla$. that if no standing time is allowed only a small amount of molybdenum (the order of 5-10 mg.) can be tolerated, but with a two hour standing perlod there is no interference at the $50 \mathrm{mg}$. per $100 \mathrm{ml}$. level $(44,45)$.

\section{Table V}

The Effect of Standing Time on the Color Intensity of an Alkaline-Peroxide Solution of Molybdenum (45)

Mg. of Mo

$\begin{array}{cccccc}\text { per } 100 \mathrm{ml} . & 0 \mathrm{hr} . & 1 / 4 \mathrm{hr} . & 1 / 2 \mathrm{hr} . & 1 \mathrm{hr} . & \frac{2 \mathrm{hr}}{0} \\ 12 & 0.002 & 0.002 & 0.002 & 0.002 & 0.001 \\ 35 & .017 & .013 & .010 & .007 & .002 \\ 50 & .025 & .018 & .014 & .009 & .001 \\ & .042 & .023 & .015 & .005 & .001\end{array}$

Anions

Rider, et al. (49), reported that acetate, chloride, nitrate, phosphate, perchlorate, and sulfate lons do not interfere appreciably. Others, however, have reported that phosphate and sulfate of this group do interfere if their concentrations are sufficlently high, and that a high fluoride concentration is undesirable since it attacks the glass $(20,44,45)$. Orleman and co-workers $(44,45)$ have reported the results listed in Table VI for the determination of uranium in the presence of several anions. The anions used were added in the form of sodfum salts and the $\mathrm{pH}$ was $12.5 \pm 0.1$. Although the authors (45) 
concluded that only phosphate, sulfate, and fluoride interfere, the data Indicate that excess amounts of chloride and nitrate may be harmful. It is of special interest to note that in extraction procedures sodium sulfate solutions which would contribute interfering levels of sulfate ion are frequently used to re-extract the uranium. It seems probable, however, that the sulfate Ion effect would be sufficiently constant to give satisfactory results when the analytical curve is prepared by the same extraction procedure.

\section{Table VI}

Effect of Antons on the Determination of Uranium by the Sodium Carbonate-Sodium Hydroxide-Peroxide Procedure $(44,45)$

( $5 \mathrm{mg}$. of $\mathrm{U}$ taken, $100 \mathrm{ml}$. final volume, measured, at $400 \mathrm{m \mu}$ )

\begin{tabular}{|c|c|c|c|c|}
\hline \multirow[b]{2}{*}{ Anion } & \multicolumn{2}{|c|}{ Mg of the Following } & \multicolumn{2}{|c|}{ Anion Concentrations } \\
\hline & $0.0 \mathrm{~g} .11$ & $108 . / 1$. & $30 \mathrm{~g} \cdot 11$ & $50 \mathrm{~g} \cdot / 1$. \\
\hline Acetate & 5.02 & 4.97 & 4.88 & 5.02 \\
\hline Chloride & 5.02 & 5.09 & 4.90 & 4.92 \\
\hline Fluoride & 5.05 & 5.05 & $\mathrm{SIO}_{2} \mathrm{p}$ & ipitate \\
\hline Nitrate & 5.02 & 4.97 & 4.92 & 4.92 \\
\hline Perchlorate & 5.02 & 5.02 & 5.00 & 5.00 \\
\hline Phosphate & 5.02 & 5.16 & 5.24 & 5.30 \\
\hline Sulfate & 5.02 & 5.05 & 5.19 & 5.28 \\
\hline
\end{tabular}

Organic Matter

Organic matter may produce a color in an alkallne-peroxide solution and thus result in interference. Removal of the organic material by oxidation with nitric acid and a nitric-perchloric acid combination (62) or by extraction with chloroform or carbon tetrachloride (48) have been recommended.

\section{$\underline{\text { Stability }}$}

The stability of the uranium color produced in this system apparently is quite good. However, the stability is dependent on the constituents present, and the presence of materials which catalyze the peroxide decomposition will cause rapid fading and perhaps prevent complete color development in the first place. Orleman (44) stated that fading takes place in a few hours but is not appreciable 
with 20-30 minutes. This probably is a realistic time for the normal sample while the reported 12 to 24 hour stability $(20,45)$ may apply to pure solutions.

Sensitivity, Precision, and Accuracy

The sensitivity depends on the wavelength used and becomes much greater as the wavelength decreases. At wavelengths much shorter than $400 \mathrm{~m} \mu$ the accuracy and precision are decreased due to $\mathrm{pH}$ dependence and absorption by other materials, including the reagents. Therefore, $400 \mathrm{~m} \mu$ represents the best compromise and is the recommended wavelength for the absorption measurements. The sensitivity also depends on the instrument and cell length used. Cells with longer light paths and instruments which deliver a narrow wavelength band give increased sensitivity. A minimum determinable concentration is reported to be $0.1 \mathrm{mg}$. per $100 \mathrm{ml}$. when $10-\mathrm{cm}$. cells are used with a $1 \mathrm{~m} \mu$ band width on the Beckman DU spectrophotometer at $400 \mathrm{m \mu}(49)$. With the same instruments and $1-\mathrm{cm}$. cells Orleman and coworkers (45) reported that $24.4 \mathrm{mg}$. of uranium per $100 \mathrm{~m} 1$. gave an absorbance of 1.000 .

Precision is within the range of instrumental reproducibility. However, the precision could be increased for higher uranium concentrations by applying the technique of differential colorimetry $(27,28,38,39)$.

The degree of accuracy obtained on relatively pure solutions is good. An average relative error, for ten determinations of different uranium concentrations, of $\pm 0.53 \%$ was obtained by Rider, et al. (49). If separations are made prior to measurement, however, an average relative error of $\pm 3 \%$ should be expected $(49)$.

\section{SODIUM HYDROXIDE-PEROXIDE METHOD}

The primary reason for the development of methods using only sodium hydroxide as the alkaline reagent was the elimination of vanadium interference. It was found that when a strongly alkaline solution is heated, the vanadium-peroxide color is discharged and gives no interference in a subsequent uranium determination. Other advantages of using a high $\mathrm{pH}$, such as the lack of $\mathrm{pH}-$ dependence and the elimination of zirconium interference $(27,46)$, have been prime factors in the acceptance of this method. The characteristics of the system are quite similar in many respects to those of the sodium carbonatesodium hydroxide system. In fact, if no foreign materials are present, the spectral absorbance characteristics appear to be identical except where the absorbance of the reagents themselves is important. Definitely, there is no significant difference at 400 m. The two systems do have some important differences with respect to interference by foreign substances.

An insignificant alteration of this method by substituting sodium peroxide for hydrogen peroxide has been used by several investigators $(3,18,19,20,26$, $32,33,40,51,52)$.

The optimum conditions for this method are a strongly alkaline solution measured at, or near, $400 \mathrm{m \mu}$. The majority of investigators, however, have used $370(5,10,15,18,21,33,68)$ or $425(3,10,18,30,32,33,65)$ instead of 
$400 \mathrm{~m} \mu(10,21)$. At $400 \mathrm{~m} \mu$ the $\mathrm{pH}$ is not important if it is 11 or higher and the sodium hydroxide concentration is not critical except to establish the minimum $\mathrm{pH}$. Five ml. of $10 \%$ (weight/volume) sodium hydroxide is a satisfactory amount except in the presence of vanadium. As in the systems previously discussed, the hydrogen peroxide concentration is not critical and $1 \mathrm{ml}$. of the $30 \%$ reagent appears to be a desirable amount.

\section{Absorption Spectra}

The absorption spectra of this system are comparable to those of the sodium carbonate-sodium hydroxide system. In fact, they are identical for a given $\mathrm{pH}$ except for the absorbance of the sodium carbonate at wavelengths shorter than $400 \mathrm{~m} \mu$. Typical spectral transmittance curves for this system are shown in Figure 10 (30). As in the other systems, the absorbance of the reagents is important at wavelengths shorter than $400 \mathrm{m \mu}$. This is especially true for hydrogen peroxide as shown in Figure 2 in the section concerning the sodium carbonate method. Therefore, measurements at the shorter wavelengths require close control of reagent concentration. It is well to note that improper corrections for the blank may give results as misleading as those obtained when the reagent concentration is not controlled. Over correction on the basis of initial peroxide concentrations instead of that remaining after the reaction, has been a common error and apparently accounts for the reported, but nonexistant, transmittance minimum at $370 \mathrm{m \mu}$ (18).

Considerably more interferences are encountered at shorter wavelengths, but the molar absorbance of the urantum species is decreased at longer wavelengths. It appears that the best compromise of these opposing factors is the use of a wavelength in the vicinity of $400 \mathrm{~m} \mu$. Another attractive feature of $400 \mathrm{~m} \mu$ is the presence of an isosbestic point at $\mathrm{a} \mathrm{pH}$ of 11 and higher, as discussed in the following section. With $\mathrm{pH}$ control and proper blank correction, Beer's law apparently is obeyed over the entire useable portion of the spectrum to an extent dependent on the band width used. A wider range of concentrations is permissible as the radiation becomes more nearly monochromatic. Specific data are not available but apparently the upper limit of linearity is in the vicinity of $35 \mathrm{mg}$. of uranium per $100 \mathrm{ml}$. when the measurements are made in $1-\mathrm{cm}$. cells at $400 \mathrm{~m} \mu$ with a Beckman Model DU or equivalent.

\section{Effect of $\mathrm{pH}$}

General information on the effect of $\mathrm{pH}$ is limited because most investigators have studied only the wavelength they proposed to use. Scattered data, however, indicates that this system is not distinguishable from the sodium carbonatesodium hydroxide system except for the absence of the spectral absorbance of sodium carbonate. The tabular data of a lone report (68) describing the $\mathrm{pH}$ on a portion of the spectrum is shown graphically in Figure 11. Although a number of unlikely irregularities appear in the data, some of the prominent characteristics of the system are obvious. At wavelengths in the region of $370 \mathrm{m \mu}$ an increase in absorbance occurs with increased $\mathrm{pH}$ over the range studied (9.4-12.5) while at $440 \mathrm{~m} \mu$ the reverse is true. The erratic behavior between these wavelengths is evidently due to some other, uncontrolled, variable. Considering the apparent variations in the absorbance readings, there is little 
reason to believe that a $\mathrm{pH}$ dependence exists in the range studied at $400 \mathrm{m \mu}$, and the original data indicates a definite lack of dependence at $p H$ values of 11.6 and higher. Other investigator's $(45,49)$ selected 11 as the lower end of the $\mathrm{pH}-$ Independent range at $400 \mathrm{m \mu}$. The above data plus additional evidence reported for the sodium carbonate-sodium hydroxide system (see Figure 8 and accompanying discussion) firmly establishes an isosbestic point at $400 \mathrm{~m} \mu$. Although analysis of the data in some reports $(5,45,48)$ Indicates a possible shift of the isosbestic point with changes in uranium concentration; the shift, if it is present, is insufficient to detract from $400 \mathrm{m \mu}$ as the most desirable wavelength. Shorter wavelengths are subject to reagent absorption while longer wavelengths yield lower sensitivity.

\section{Effect of Reagent Concentration}

The reagent concentrations are not critical, as long as a minimum concentration is maintained, when the measurements are made at $400 \mathrm{m \mu}$ or longer wavelengths. At $370 \mathrm{~m} \mu$ or shorter wavelengths, the concentrations are important due to the absorbance of the reagents themselves. This is especially true for the peroxide. Enough peroxide must be added to allow maximum color development, which depends on the uranium concentration, but a large excess is to be avoided because of bubble evolution. The optimum amount appears to be $1 \mathrm{ml}$. of the $30 \%$ reagent. A sufficient amount of sodium hydroxide to give a pH of 11 or greater is necessary for optimum color development. For pure solutions, an excess of $5 \mathrm{ml}$. of $10 \%$ sodium peroxide (wt./volume) is sufficient, but if the elimination of vanadium interference is desired, an excess of 15-20 ml. of a $50 \%$ sodium hydroxide solution should be used.

Sodium Hydroxide

Much of the Investigation concerning the caustic concentration has been directed toward the determination of the amount necessary to eliminate the vanadium interference and will be discussed more fully in that section. The effect of sodium hydroxide on the uraniumperoxide system is strictly a pH effect except where the absorbance of this reagent is important. Literature value is 1 imited in this respect because usually the amount of sodium hydroxide is given with. no mention of the resulting $\mathrm{pH}$. Begg and associates (5) included data which indicated no concentration effect for 5,10 , and $15 \mathrm{ml}$. of $10 \%$ sodium hydroxide $(w / v)$ at $370 \mathrm{~m} \mu$ and this has been substantiated by other investigator $(33,69)$. A similar observation has been reported at $425 \mathrm{m \mu}$ where only a small effect was noted $(30,33,65)$. Kaufman and Galwanek, $\mathrm{Jr} \cdot(33)$ found that a minimum sodium hydroxide concentration of $4 \%$ is necessary, but a variation of 4 to $10 \%$ makes no difference. The concentrations discussed above should give $\mathrm{pH}$ values in the region of $12.2-12.5$ and produced what the investigators deemed to be negligible variation. At $400 \mathrm{mH}$ the minimum amount would be lowered to perhaps $1 \mathrm{ml}$. of a $10 \%(\mathrm{w} / \mathrm{v})$ sodium hydroxide solution ( $(8 \theta)$. With due reference to the literature, $5 \mathrm{ml}$. of the $10 \%$ solution, in excess of that required for neutralization, per $100 \mathrm{ml}$. of solution is recommended except where vanadium interference is a problem. A much larger amount in the order of 
15-20 ml. of a $1: 1$ ( $w: v$ ) sodium hydroxide solution is necessary to eliminate vanadium interference $(10,30,65)$. In any case, excess sodium hydroxide does not harm.

\section{Peroxide}

The concentration of either hydrogen peroxide $(5,30,33,69)$ or sodium peroxide (33) can vary over a rather wide range if a wavelength of $400 \mathrm{m \mu}$ or longer is used. At shorter wavelengths the concentration after reaction, is important due to the absorbance of the peroxide itself (69). Huston ( 30 ), who compiled the only extensive peroxide data avallable, found that $1 \mathrm{ml}$. of $30 \% \mathrm{H}_{2} \mathrm{O}_{2}$ could be used with a maximum of about $40 \mathrm{mg}$. of uranium. Excess peroxide does no harm until the point is reached where bubble formation is troublesome. A recommended volume which gives a reasonable margin of excess without the latter difficulty is $1 \mathrm{ml}$. of the $30 \%$ reagent for $10-15 \mathrm{mg}$. of uranium. The volume need not be exact unles's the measurement is made at wavelengths shorter than $400 \mathrm{~m} \mu$.

\section{Interferences}

The interferences encountered in this system are much the same as in the other alkaline systems but speciflc data to base rellable evaluations on is more limited. The absence of carbonate does allow the presence of some materials, or a higher concentration of them, which would precipitate if it were present. This is especially true of the alkaline earths. The main advantages are the elimination of vanadium interferences by boiling the sodium hydroxide solution and the absence of zirconium interference due to the formation of a soluble zirconium-peroxide complex. Tables VII and VIII represent a compilation and summary of the selected data avallable for this system. Where further elaboration is considered to be desirable, the materials are treated separately, or in groups in the following discussion. In addition, certain elements should be considered because of their characteristic behavior. Osmium, palladium, platinum, rhodium, and ruthenium are reported to precipitate with peroxide in an acidic solution but form a color in an alkalineperoxide solution (35). The color, the characteristics of which are not stated, is discharged by the addition of ammonium chloride. Elements other than those 1isted in the table which are reported (48) to precipitate in an alkaline solution are: beryllium(II), bismuth(III), cadmium(II), germanium(II), lanthanum(III), platinum(II), samarium(III), scandium(III), tantalum(III), and yttrium(III)。Although none of these elements were investigated for this particular system and may be of no consequence in the uranium procedure, they should be considered as possible interferences.

The list of possible interferences is quite sizable but for a given sample many become Insignificant because of their absence or low concentration relative to that of uranium. Perhaps the most significant study of interferences which are likely to be encountered was made by Huston (30). The elements studied were those found by spectrographic analysis to be present in chemical $\mathrm{K}-65$, the carbonate leached residue from a nitric acid digestion of pitchblende ore. A large portion of the interference data presented herein is based on Huston's work. 
Table VII. The Effect of Anions, Ammonia, and Other Materials on the Determination of Uranium by the Sodium Hydroxide-Peroxide Procedure

\begin{tabular}{|c|c|c|c|}
\hline Material & References & $\begin{array}{l}\text { No effect at } \\
\text { this level } \\
g . / 100 \mathrm{ml} \text {. }\end{array}$ & Remarks \\
\hline $\begin{array}{l}\text { Ammonia } \\
\text { Bicarbonate } \\
\text { Carbon Dioxide } \\
\text { Carbonate } \\
\text { Chloride as } \mathrm{NaCl} \\
\text { Nitrate as } \mathrm{NaNO}_{3} \\
\text { Organic Matter } \\
\text { Peroxide, } 3 \% \\
\text { Phosphate } \\
\text { Sulfate } \mathrm{Na}_{2} \mathrm{SO}_{4}\end{array}$ & $\begin{array}{c}69 \\
51,69 \\
69 \\
30,69 \\
3035 \\
20,35,51,62 \\
51 \\
20,65 \\
30\end{array}$ & $\begin{array}{l}\text { Indefinite } \\
\text { Indefinite } \\
\text { Indefinite } \\
\text { Indefinite } \\
5.0 \text { and } 10.0 \\
5.0 \\
\ldots \ldots \ldots \\
0.00 \\
5.0\end{array}$ & $\begin{array}{l}\text { PH effect } \\
\text { pH effect } \\
\text { pH effect } \\
\text { May prevent discharge of } v \text { color } \\
\text { Limit probably much higher } \\
\text { Limit probably much higher } \\
\text { May give color; should remove } \\
\text { May give color } \\
\text { Interferes if } v \text { is present } \\
\text { Limit probably much higher }\end{array}$ \\
\hline
\end{tabular}


Table VIII. The Effect of Various Metals on the Determination of Uranium by the Sodium Hydroxide-Peroxide Procedure ${ }^{a}$

\begin{tabular}{|c|c|c|c|c|}
\hline \multirow{4}{*}{$\begin{array}{c}\begin{array}{c}\text { Element } \\
\text { "E }\end{array} \\
\qquad{ }_{\mathbf{A u}^{\mathrm{b}}}^{\mathrm{b}}\end{array}$} & \multirow[t]{2}{*}{$\begin{array}{l}\text { \% Error in detn. of } \\
10 \mathrm{mg} \text {. U in presence of } \\
10 \mathrm{mg} \text {. "E" in } 100 \mathrm{ml} \text {. }\end{array}$} & \multicolumn{2}{|c|}{$\begin{array}{c}\text { Maximum "E" wi thout } \\
\text { interference, } \\
\text { mg. } / 100 \mathrm{ml} \text {. }\end{array}$} & \multirow[t]{2}{*}{ Remarks } \\
\hline & & $425 \mathrm{~m}$ & $370 \mathrm{~m}_{4}$ & \\
\hline & 250.0 & 0.1 & $\ldots$ & Precipitates \\
\hline & $\ldots$ & $\cdots$ & ... & $\begin{array}{l}\text { Reduced to metallic } \\
\text { state }\end{array}$ \\
\hline A1 & None & $\cdots$ & $\ldots$ & $\ldots \ldots \ldots$ \\
\hline As & -8.0 & 8.0 & $\ldots$ & $\ldots \ldots \ldots \ldots$ \\
\hline B & None & ... & ... & $\ldots \ldots \ldots$ \\
\hline $\mathbf{B a}$ & $>250.0$ & 1.0 & $\ldots$ & Precipitates \\
\hline $\mathbf{C a}$ & +21.0 & 1.0 & $\ldots$ & Precipitates \\
\hline $\mathrm{Ce}^{\mathrm{c}}$ & +10.0 & 0.5 & $3.0^{\mathrm{d}}$ & Precipitates, color \\
\hline Co & -88.0 & $<0.1$ & $\ldots$ & Precipitates \\
\hline $\mathrm{Cr}$ & +430.0 & $<0.1$ & $\ldots$ & Color \\
\hline $\mathrm{Cu}$ & -97.0 & 0.5 & Trace $^{e}$ & $\begin{array}{l}\text { Precipitate, color, } \\
\text { catalysis }\end{array}$ \\
\hline $\mathbf{F e}$ & $>250.0$ & 0.5 & $0.2^{d}$ & $\begin{array}{l}\text { Precipitate, colloid, } \\
\text { catalysis }\end{array}$ \\
\hline $\mathbf{G a}_{2}$ & None & $\cdots \cdot$ & $\ldots$ & Precipitate $\mathrm{f}^{\mathrm{f}}$ \\
\hline $\mathrm{Hg}^{\mathrm{b}}$ & $\cdots \cdots$ & $\cdots$ & $\cdots$ & $\begin{array}{l}\text { Reduced to metallic } \\
\text { state }\end{array}$ \\
\hline In & None & $\cdots$ & $\cdots$ & $\begin{array}{l}\text { In (II) and in (III) } \\
\text { precipitates }\end{array}$ \\
\hline Mg & +14.0 & 1.0 & $\cdots \cdot$ & Precipitates \\
\hline Mn & $>250.0$ & $<0.1$ & $\ldots$ & $\begin{array}{l}\text { Precipitate, colloid, } \\
\text { catalysis }\end{array}$ \\
\hline Mo & -5.0 & 8.0 & $3.0^{\mathrm{d}}$ & $\begin{array}{l}\text { Yellow color fades on } \\
\text { standing }\end{array}$ \\
\hline $\mathbf{N b}$ & $\cdots \cdot$ & $\begin{array}{l}\text { esti } \\
\text { mg. }\end{array}$ & $\begin{array}{l}\text { d } 8-10 \\
\mathrm{ml}\end{array}$ & Weak yellow color ${ }^{f}$ \\
\hline Ni & +8.0 & 0.5 & $\ldots$ & Precipitates \\
\hline $\mathbf{P}$ & None & $\cdots$ & ... & $\because \cdots \cdots \cdots$ \\
\hline $\mathbf{P b}$ & None & 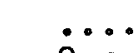 & $\ldots$ & Precipitates $\mathbf{I}$ \\
\hline Si & -5.0 & 8.0 & $\cdots$ & $\ldots \ldots \ldots$ \\
\hline Sn & +10.0 & 1.0 & $\cdots$ & Precipitates \\
\hline Sr & None & $\ddot{\cdots} \cdot$ & $\cdots$ & $\ldots \ldots \ldots$ \\
\hline The & +7.0 & 8.0 & $\cdots$ & Precipitates \\
\hline Ti & +50.0 & 0.1 & $\ldots$ & Precipitates \\
\hline $\mathbf{v}$ & None up to $50 \mathrm{mg}$. & $100 \mathrm{~m}$ & treated & properly - see text \\
\hline $\mathbf{Z n}$ & None & $\ldots$ & $\ldots$ & $\ldots \ldots \ldots$ \\
\hline $\mathbf{Z r}$ & None & $\ldots$ & $\cdots$ & $\ldots \ldots \ldots$ \\
\hline
\end{tabular}


Table VIII contd.

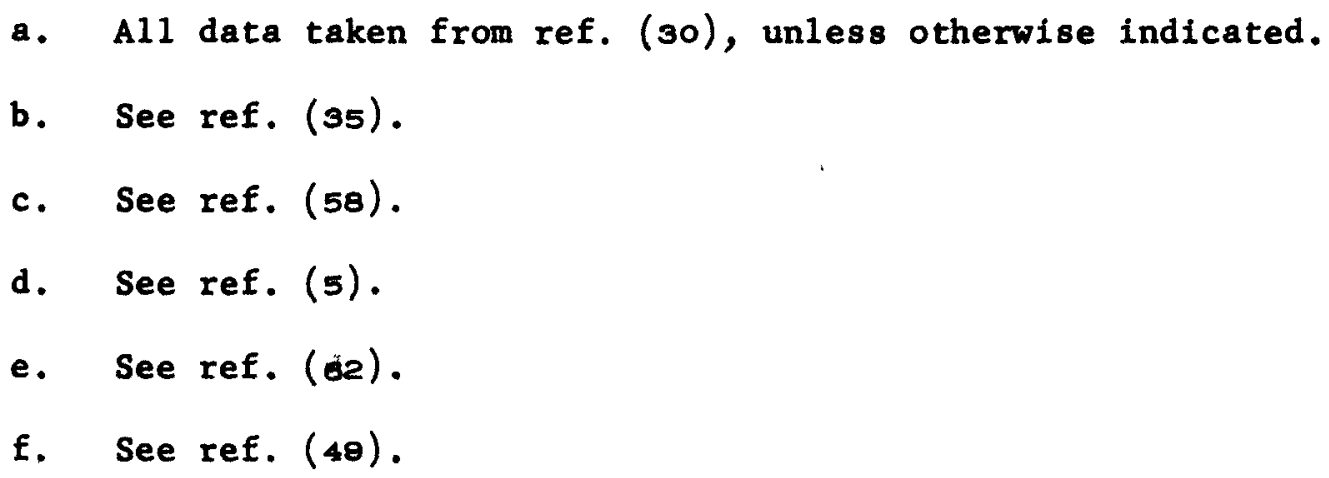


Magnesium, Calcium, Strontium, and Barium

The alkaline earths may interfere by precipitation as the hydroxide or peroxide $(30,68)$. The removal of the precipitates by filtration may give low results due to occlusion of uranium in the precipitate, but high results are obtained if the precipitate is not removed (30). With due consideration, these elements may be removed by a carbonate separation, and the excess carbonate destroyed before the uranium is measured. (See discussion of alkaline earth interferences in the sodium carbonate-peroxide system.) An oxalate separation of calcium in acetic acid solution also has been recommended $(69)$. The limits of allowable concentrations have been set at $1.0 \mathrm{mg}$. per $100 \mathrm{ml}$. for barium and magnesium and greater than $10 \mathrm{mg}$. for strontium ( 30$)$.

Vanadium

Vanadium seriously interferes in the sodium hydroxide-peroxide system because of its spectral absorbance $(30,51,52)$. The proposed maximum tolerable amounts without special treatment have varied from $10 \mu \mathrm{g}$. per $100 \mathrm{ml}$. at $370 \mathrm{m \mu}$ (5) to $1 \mathrm{mg}$. at $425 \mathrm{m \mu}$ (30). In fact, al though the distribution coefficient of uranium is approximately fifty times more favorable for extraction than that of vanadium, sufficient vanadium may be extracted by ethyl ether to give poor uranium results. Much the same situation prevails with penta-ether and TBP except that the use of tartaric acid prevents the extraction by reducing the vanadium(V) to vanadium(IV). The spectral transmittance curves of uranium and vanadium in this system, as reported by Center (10), are compared in Figure 12. It is obvious that there is little difference in the absorbance of uranium and vanadium on a weight per volume basis. However, the seriousness of the vanadium interference has not always been recognized because the vanadium color appears much less intense to the eye than does the uranium color. When the presence of vanadium is questionable, a simple variation in reagent addition will provide a convenient test for its presence. If the peroxide is added before the solution is made alkaline, vanadium is easily detected by the formation of a characteristic yellow color.

A further complication of a system containing vanadium is that the color intensity of the vanadium species is quite temperature-dependent (52). This, however, has been used to advantage after it was observed that the vanadium color is completely discharged by heating in a strongly alkaline solution $(18,18,20,30,51,53)$. To furnish the desirable medium, strongly basic solutions of lithium $(65), \operatorname{sodium}(18,20,50,51,52,53,58)$, or potassium (65), hydroxide with either sodium $(18,51,52)$ or hydrogen $(20,30,53)$ peroxide have been used. None of these are superior to the sodium hydroxide-hydrogen-peroxide system. It is not clear from the available data whether or not the presence of carbonate prevents complete discharge of the vanadium color in this system, but it is known that boiling will not eliminate the color in the carbonate system (18).

Some investigators have employed a preliminary boiling of the alkaline solution prior to the addition of the peroxide $(30,65)$. In this case, 
after the peroxide addition the solution must be reheated to just short of boiling and cooled before the uranium color is measured. Other have boiled the peroxide solution with a subsequent addition of more peroxide before the measurement $(18,33)$. If the latter method is used, it makes no difference whether the solution is heated just to boiling or boiled for three minutes as long as more peroxide is added to counteract the bleaching of the uranium color (33). Using this procedure, Goldbeck, et al. (18) found that $106 \mathrm{mg}$ of vanadium had no effect on the uranium color. If the former procedure of boiling the alkaline solution, adding peroxide, and reheating is used, the conditions are more critical (30). It has been established that a minimum of one minute preliminary boiling of the alkaline solution is necessary, but a longer period of two minutes makes no difference. The final heating is more critical and a standardization of both time and temperature are necessary to give reproducible results. When the final heating was allowed to proceed until a temperature of $85^{\circ} \mathrm{C}$. was reached the presence of $53 \mathrm{mg}$. of vanadium per $100 \mathrm{ml}$. of solution had no effect on the results. The average relative error obtained by duplicate measurements of solution containing seven different concentration combinations of uranium and vanadium was $0.8 \%(30)$.

Either of the above methods gives reliable results if executed properly. The procedure of boiling the alkaline peroxide solution for one to three minutes, cooling and adding additional peroxide probably is preferable because the conditions are far less critical. The amount of sodium hydroxide needed to discharge the vanadium color is greater than that needed for color development in a vanadium free system as discussed under reagent concentrations. Reports indicate that a volume of 15-20 $\mathrm{ml}$. of $1: 1(w: v)$ sodium hydroxide is sufficient but that the minimum amount necessary may be dependent on the varadium concentration $(19,30,65)$.

Physical separation of the uranium and vanadium can be accomplished by co-precipitating uranium and aluminum as phosphates and leaving the vanadium in solution, as described by Foster et al. (15). This separation is time consuming but the dissolved precipitate can be treated directly with the sodium hydroxide-peroxide procedure.

\section{Chromium}

The behavior of chromium in this system is essentially the same as in the sodium carbonate system previously discussed and will not be repeated here in detail. Again, the element interferes because of the color of the chromate $\operatorname{Ion}(10,20,30,33,33,51,89)$. If the spectral transmittance curves of chromium and uranium shown in Figure 12 (10) are compared, it is obvious that only a very small amount of chromium can be tolerated because of its strong spectral absorbance relative to that of uranium. At 425 max the maximum allowable amount is reported to be less than $0.1 \mathrm{mg}$. per $100 \mathrm{ml}$, and the limit is much lower at $400 \mathrm{m \mu}(30,33)$. Center (10) measured the absorbance of each sample at both 370 and $425 \mathrm{~m} \mu$ in order to detect the presence of chromium which otherwise might go unnoticed. A significant difference in the apparent amount of uranium found at the two wayelengths provided a warning that further separation was necessary. 
Manganese

The behavior of manganese in this system is much the same as in the other systems $(30,33)$. The colored colloldal suspension which gives high results if it remains and low results if it is coagulated and filtered is somewhat more troublesome in this system. The maximum concentration 1 imit has been set at 1 ess than $0.1 \mathrm{mg}$. per $100 \mathrm{ml}$. (30). Electrolysis and carbonate or ammonia precipitations have been used as methods for separation $(44,45)$, but complete removal is difficult ( 30$)$.

Iron, Cobalt, and Nickel

These elements precipitate under the conditions employed in this method and interfere with the absorbance measurements. High values are obtained if they are not coagulated and removed, but low results are 11 kely if they are removed in this manner (3o). A sodium hydroxide-peroxide impregnated filter is often used for filtering these materials $(10,15)$.

Iron, especially, tends to form a colored colloidal suspension, and extreme care must be taken to coagulate the material $(6,10,30,33,35,58,69)$. Center (10) states that if colloidal iron is present the results are in less error if the measurement is made at 370 instead of $425 \mathrm{m \mu}$. Colloid formation of iron concentration ranging from 0.25 to about $5 \mathrm{mg}$. per $50 \mathrm{ml}$. is reported to produce an approximately constant error ( 5 ), and direct correction of the absorbance measurement for the contribution of the collold has been proposed (17). Aside from the colloid effect, the presence of even very small amounts of iron may cause trouble because of its catalytic effect on the decomposition of peroxides $(20,48,68)$. Typical of the proposed maximum allowable amounts of iron are $0.2 \mathrm{mg}$. (5) and $0.5 \mathrm{mg}$. (30) per $100 \mathrm{ml}$. at 370 and $425 \mathrm{~ms}$, respectively.

Cobalt and nickel would be expected to behave similarly to iron except for the color of the colloid. However, Huston (30) observed that cobalt gives extremely low results. The explanation is not evident but could be due to the formation of a rapidly settling precipitate which and occludes considerable uranium. The nickel behaves in a more normal manner and gives high results (30). Maximum 1 imits of $0.5 \mathrm{mg}$. and $1 \mathrm{ess}$ than $0.1 \mathrm{mg}$. per $100 \mathrm{ml}$. for nickel and cobalt, respectively, were proposed (30), but it seems doubtful that these are representative data. Each situation will probably give different errors depending on the degree of coagulation. If the precipitates are completely coagulated and removed, then both cobalt and nickel can be expected to cause low results (20).

Carbonate separations have been used for solutions containing iron, cobalt, and nickel (20). An equally good separation probably could be obtained by adding the peroxide prior to making the solution alkaline when only sodium hydroxide is used. The addition of tartrate to complex the iron has been proposed as a means to eliminate the necessity of a separation (20). However, the iron-tartrate complex is known to have an appreciable spectral absorbance at $400 \mathrm{m \mu}$ in an ammonium hydroxide solution and, presumably would behave similarly in a sodium hydroxide medium. 


\section{Copper}

The interference of copper may be due to precipitation (e8), spectral absorbance by the copper ion $(30,35)$, catalysis of peroxide decomposition $(30,49,8)$ or a combination of these. Copper will precipitate under the conditions of this system, but at the high alkalinity the precipitation is incomplete (35). The residual copper, or small amounts present at the outset, may then produce small positive errors by spectral absorption or negative errors by causing the peroxide to decompose. The latter effect, evidenced by a fading of the uranium color ten minutes after development, has been reported for solutions containing only the trace amounts present in distilled water drawn from a copper-coiled still (82). The fact that catalysis is not always effective is verified by the high permissible level of $0.5 \mathrm{mg}$. of copper per $100 \mathrm{ml}$. observed by Huston (30).

Copper is usually removed by an ammonia separation (89).

Thorium

Thorium forms a precipitate in an alkaline-peroxide solution and may be removed by centrifuging or filtering. Some uranium loss usually accompanies the separation and one or two re-precipitations, depending on the bulk of the precipitate, followed by filtration through a sodium hydroxide-peroxide impregnated paper have been

Ammonia and Ammonium Salts

These may interfere by producing a $\mathrm{pH}$ below that needed for complete color development. The amounts that can be tolerated is increased by the addition of more base (

Anions

Nitrate, sulfate, and chloride are reported to give no interference for all the concentrations investigated $(5,20,30,82,65,69)$. Huston ( 30 ) found that the addition of $5 \mathrm{~g}$. of sodium nitrate, sodium sulfate, or sodium chloride per $100 \mathrm{ml}$. of solution did not affect the uraniumm peroxide absorbance and others (e8) have observed the limit for sodium chloride to be above $10 \mathrm{~g}$. Considerably higher concertrations of nitrate and sulfate, added as $10 \mathrm{ml}$. of the concentrated acid, have appeared to give no effect but the results are clouded by variations introduced to eliminate vanadium interference (65).

Bicarbonate may produce a lower pH than is needed for full color development $(51,89)$, and carbonate may prevent complete discharge of the vanadium color ( $8 \theta$ ). Both of these may be removed by bolling the acidic solution prior to neutralization.

Phosphate has been reported to give no interference at low concentrations (20), but there is an indication that $2 \mathrm{mg}$. of phosphate in $100 \mathrm{ml}$ of solution may give appreciable positive errors when vanadium is present (65). The amount of error was reported to increase with increased vanadium concentration 
but the data is questionable, because the final heating to discharge the vanadium color was not sufficiently controlled. The indicated error, in fact, may be due to the vanadium itself. If higher concentrations of phosphate are detrimental, there must be a point at which the effect becomes non-concentration-dependent because the sodium hydroxide procedure has been applied to uranium phosphate precipitates $(15,16)$.

\section{Carbon Dioxide}

If the alkaline solutions are exposed to the air for several days, the absorption of carbon dioxide can reduce the pH sufficiently to cause low answers.

\section{Hydrogen Peroxide, Dilute}

Rodden (51) has observed the formation of a yellow color when some commercial $3 \%$ hydrogen peroxide was treated with an alkali. This has never been reported for the $30 \%$ product. The strength of the unstable reagent should be checked to detect low assay material that occasionally may be received (62).

\section{Organic Material}

A color may be obtained if peroxide is added to a solution containing organic material (35). Since this interference has been most frequently observed after an ether extraction, a nitric or perchloric acid treatment of the extract has been recommended $(5,20,51,62)$. An alternate method of removing the organic is to wash the extract with carbon tetrachloride or chloroform (48). Only insignificant trace amounts of uranium are said to be extracted by carbon tetrachloride or chloroform (48).

\section{Stability}

The stability of the system depends on the purity of the solution. If the solutions are pure the color is stable for at least 10 to 12 hours $(33,52,62)$. In practical applications, stability for 20 minutes to one hour probably is more realistic (5). In the presence of materials which catalyze the peroxide decomposition, fading may be accelerated and in extreme cases the maximum color may not be developed at all. Hence, although the system is reasonably stable it seems advisable to measure the samples as soon after color developments as possible. One reported exception to the rule is in a differential colorimetric method for large amounts of uranium following a double ethylacetate extraction, where Guest and Zimmerman (21) observed immediate fading on peroxide addition. Since the slight fading proceeded for only a short length of time, it was recommended that the solutions be allowed to stand for one or two hours before measuring. 
Sensitivity, Precision, and Accuracy

Sensitivity

The sensitivity depends on the $\mathrm{pH}$ and the characteristics of the measuring system such as spectral bandowidth, wavelength, cell dimensions, and instrument sensitivity. The $\mathrm{pH}$ effect has been discussed in a previous section but may be summarized as follows: at wavelenghts in the vicinity of $425 \mathrm{m \mu}$, sensitivity varies inversely with $\mathrm{pH} ;$ at $400 \mathrm{m \mu}$ sensitivity is independent of $\mathrm{pH}$ if the $\mathrm{pH}$ is 11 or higher; and at wavelengths in the vicinity of $370 \mathrm{~m} \mu$ sensitivity varies directly with $\mathrm{pH}$. With respect to the measuring system it may be said that sensitivity varies inversely with wavelength and directly with the length of light path provided by the cell. The sensitivity data reported below were obtained on a Beckman DU spectrophotometer with $1-\mathrm{cm}$. cells, but data obtained on other instruments are available $(5,18,1)$. Sensitivity values in terms of the weight of uranium per $100 \mathrm{ml}$. required to give a calculated absorbance of 1.00 are $16 \mathrm{mg}$. at $370 \mathrm{m \mu}$ with a solution blank (5), and $41 \mathrm{mg}$. at $425 \mathrm{m \mu}$ with a water blank (30). I obtained a corresponding value of $24.4 \mathrm{mg}$. at $400 \mathrm{m \mu}$ with a solution blank and a band width of less than $0.5 \mathrm{~m}_{4}$.

\section{Precision}

No complete precision study of the colorimetric measurement alone has been reported. Begg, et al. (5), in studying the effect of sodium hydroxide concentration on pure solutions obtained data that indicate the precision to be within the reproducibility of the instrument readings. If separations are necessary or if heating is employed to eliminate vanadium interference, the prectsion for the overall procedure will be reduced by an amount depending on the nature of the additional manipulations and the care of the analyst. Guest and Zimmerman (21) have reported a standard deviation of about $0.5 \%$, relative, for an analysis involving an ethyl acetate extraction and measurement at 370 This deviation was decreased to about $0.2 \%$ by the application of differential colorimetry techniques (21): a phenomenon which is theoretically sound and, in most cases, experimentally obtainable $(27,28,38,39)$. It should be noted that at wavelengths shorter than $400 \mathrm{m \mu}$ the precision will be directly dependent on the control of reagent concentration, and that at $400 \mathrm{m \mu}$ conditions can be readily established to eliminate this relationship. In our laboratory, a precision of $\neq 0.1 \mathrm{mg}$ of uranium at the $95 \%$ confidence level, for a single determination, was obtained over the range of $0-20 \mathrm{mg}$. (68). This figure includes variations resulting from a TBP extraction separation as well as the colorimetric measurement.

\section{Accuracy}

If no separation steps are involved, the average relative error for this system is of the order of $\pm 1 \%$. On duplicate determinations of seven samples with the uranium and vanadium concentrations varying from 5 to 26 and 1 to $100 \mathrm{mg}$. per 100 , respectively, Huston (30) obtained an average 
relative error of $\pm 0.8 \%$. Another investigator (69) reported an average relative error of $\pm 1.2 \%$ in the analysis of ten solutions containing nine different uranium concentrations and no vanadium. These relative errors were obtained on the Beckman Model DU spectrophotometer at $425 \mathrm{~m}_{\mu}$ and the Lumetron Model 402 photoelectric colorimeter at $390 \mathrm{~m}_{\mu}$, respectively. If separations are involved, it seems reasonable to expect a $\pm 3 \%$ relative error.

\section{OTHER ALRALINE-PEROXIDE METHODS}

A number of other methods, most of which represent modifications of the previously discussed systems, have been reported. Some of these provide real differences that may be advantageous in special situations, but most of them represent only the substitution of an equivalent reagent. Thus, the use of lithium $(65)$ or potassium $(52,65)$ hydroxide should behave as the sodium hydroxide system. Also, the combination of sodium carbonate-sodium peroxide (18) should have the same characteristics as the sodium hydroxide-sodium carbonatehydrogen peroxide mixture. The sodium carbonate-sodium bicarbonate system $(4,30,59,60,63,69)$ has been discussed as a special case of the carbonate method. The distinct methods are discussed briefly in this section.

\section{Ammonium Hydroxide-Potassium Carbonate-Peroxide Method}

Schwebel (57) reported a method in which the acidic uranium solution is rendered alkaline with ammonium hydroxide and a total of $20 \mathrm{ml}$. of a saturated potassium carbonate solution is added to provide a carbonate medium. Hydrogen peroxide is added to develop the color. No reasons are given for the choice of this system and no advantages are apparent. Since an excess of $0.5 \mathrm{ml}$. of ammonium hydroxide is added in the procedure, the characteristics should be essentially the same as the buffered, sodium carbonate systems. However, in a straight carbonate procedure the use of the potassium salt offers the possibility of a more concentrated reagent than could be used with sodium carbonate.

Ammonium Hydroxide-Tartrate-Peroxide Method

This system was developed for solutions containing interfering amounts of calcium and iron such as those obtained from an ether extraction using calcium nitrate as a salting agent. The addition of tartrate produces an iron complex with the spectral characteristics shown in Figure 13 (84) and a non-absorbing calcium complex. The absorbance of the iron-tartrate species prohibits the use of $400 \mathrm{~m}_{\mu}$ and shorter wavelengths but should not affect measurements at $420-425 \mathrm{~m}_{\mu}$. A reported $5 \%$ decrease in the absorbance of the uranium color (64) must be due to competition of the tartrate for the uranyl ion $(13,14)$ but a firm conclusion can not be made on available data. Chloride and phosphate are reported to interfere ( 52$)$, and there is some question about the reproducibility of the method $(44)$.

In the presence of ammonium sulfate, frequently used to remove uranium from organic solvents, ammonium hydroxide is said to increase the sensitivity over that obtained with sodium hydroxide at $420 \mathrm{~m} \mu(52,64)$. Once again, the real 
reason probably is a decreased $\mathrm{pH}$ which would be expected to increase the absorbance at that wavelength.

Ammonium Carbonate-Peroxide and Ammonium Hydroxide-Carbonate-Peroxide Systems

These systems are essentially the same except that some investigators prefer to neutralize the acidic solution with ammonium hydroxide and then add the ammonium carbonate $(52,61)$. The biggest impetus to the use of ammonium carbonate was the use of both the ammonium and sodium salts by Rosenheim and Daehr (54) in one of the early investigations of the system. Arnold and Pray (2) have made the most detailed study, using ammonium carbonate, as in indirect method for sodium. Smales (61) proposed the addition of citrate ion to help curb the evolution of bubbles, but some consideration probably should be given to the stability of the uranyl citrate complexes (14).

Over-a11, there seems to be no advantage in the ammonium carbonate system and many investigators have preferred the sodium salt $(2,51,52,56,61)$. A definite disadvantage of the ammonium ion is a lower and less easily controlled pH. 


\section{References}

1. Aloy, J., Bul1 soc. chim. France, 27, 734-35 (1902).

2. Arnold, E. A., and Pray, A. R., Ind. Eng. Chem., Anal. Ed., 15, 294 $(1943)$.

3. Bassett, L. G., Pflaum, D. J., Rutman, R. J., Rodden, C. J., and Furman, N. H., "Manual of Analytical Methods," Vol. I, Madison Square Area, Manhattan District Corps of Engineers, A-2912 (1946).

4. Ibid., Vol. III, Part 1 .

5. Begg, M. R., Williams, A. F., and Wood, G. A., Dept. of Scientific and Industrial Research, Chemical Research Laboratory, Teddington, Middlesex, CRL-AE-21 (1948).

6. Brackenbury, G., Dept. of Mines and Technical Surveys, Mines Branch, Ottawa, Canada, TR-73/51 (1951).

7. Bullwinke1, E. P., The Merri11 Co., RMO-2614 (1954).

8. Bursta11, F. H., and Ryan, W., Ministry of Supply, United Kingdom, BR-743 (1949).

9. Cassidy, H. G., Dept. of Chemistry, Yale University, A- 337 (1940).

10. Center, E. J., Batteile Memorial Institute, BMI-97 (1947).

11. Clinton Engineering Works, Tennessee Eastman Corp., C-4.360.1 (1945).

12. Corpel, J., Bul1. soc. chim. France, 752-54 (1953)。

13. Feldman, I., and Havil1, J. R., J. Am. Chem. Soc., 76, 2114-117 (1954).

14. Feldman, I., Havi11, J。 R。, and Neumann, W. F。, J. Am. Chem. Soc., 76, 4726-32 (1954).

15. Foster, M. D., Grimald1, F. S., and Stevens, R。E., U.S.Geological Survey, $\underline{M}-\underline{4569}$

16. Foster, M. D., and Stevens, R. E., U.S. Atomic Energy Commission, AECD-2630 (1949).

17. Goldbeck, C. G., Martinez, Z, and Degroot, T。 M., New Brunswick Laboratory, U.S. Atomic Energy Coumission, NYO-2012 (1950).

18. Goldbeck, C. G., Petretic, G. J., Minthorn, M。 L., and Rodden, C. J., Madison Square Area, Manhattan District Corps of Engineers, A-1074 (1954). 
19. Goldbeck, C. G., and Rodden, C. J。, U。S.Atomic Energy Commission, AECD-2510 (1944).

20. Grunewald, A. L., Fairchild Engine and Airplane Corp., NEPA-470 (1948).

21. Guest, R. J., and Zimmerman, J。, Ana1. Chem。27, 931-36 (1955)。

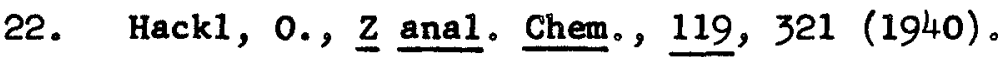

23. Hamaker, J. W., and Koch, C. W., U.S.Atomic Energy Commission, MDDC-1211 (1947).

24. Harvey, C. 0., Bull. Geol. Survey Gt。 Brit。, No。 3, 43-57 (1950).

25. Hedvall, J., Z anorg。 u。aligem。 chem。, 146, 225 (1952)。

26. Hillebrand, W. F., Lundel1, G.E. F。, Bright, H. A., and Hoffman, J. I., "Applied Inorganic Analysis," 2nd ed。, New York, John Wiley and Sons, Inc. (1953)。

27. Hiskey, C. F., Anal. Chem. 21, 1440-446 (1949)。

28. Hiskey, C. F。, Rabinowitz, E., and Young, I. G., Anal. Chem. 22, 1464-470 (1950)。

29. Huffman, E。 Ho, and Pascual, Jo, University of California Radiation Laboratory, B-25, RL-3.6.25 (1944)。

30. Huston, S. H., Mallinckrodt Chemical Works, unpublished work (1947)。

31. Ingram, W. W., Madison Square Area, Manhattan District Corps of Engineers, A-1064 (1945)。

32. Kaufmann, D., Massachusetts Institute of Technology, MITG-A32 (1947).

33. Kaufmann, $D_{\circ}$, and Galvanek, $\mathrm{Jr}, \mathrm{P}_{\circ}$, Massachusett 8 Institute of

- Technology, MITG-A67 (1950); (also U。S。Atomic Energy Commission, AECD-3137 (1951)。

34. Lang, G. P., Mallinckrodt Chemical Works, unpublished work (1949).

35. Lunde11, G. E. F。, and Hoffman, J。 I., "Out IInes of Methods of Chemical Analysis," New York, John Wiley and Sons, Inc。(1938)。

36. McBee, E. T., and Welch, Z. D., Purdue University, M-2103 (1945).

37. Meyer, R. J., "Gmelin's Handbuch der Anorganishcen Chemie," 8th ed., System No. 55, Lelpzig-Ber1in, Verlag Chemie, 1936; transiation by O'Brien, I. C., and Feldman, Co, Technical Information Service, U.S. Atomic Energy Comission, TID-82. 
38. Milner, G. W. C., and Phennah, P. J., Analyst 79, 414-24 (1954).

39. Neal, W. T. L., Analyst 79, 403-13 (1954).

40. New Brunswick Laboratory, U.S. Atomic Energy Commission, AECD-2640 (1949).

41. Orleman, E. F., C1inton Engineering Works, Tennessee Eastman Corp., CD-2228 (1945).

42. Ibid., CD-2244 (1945).

43. Ibid., CD-2253 (1945).

44. Ibid., CD-2270 (1945).

45. Orleman, E. F., Wiber $1 y$, S. E., Coleman, C. F., and Smales, A. A., Clinton Engineering Works, Tennessee Eastman Corp., C-4.360.7 (1945).

46. P1ssar jewsky, L., 2 anorg. Chem. '25, 395 (1900).

47. Raisen-Streden, R., Anal. Chim. Acta, 4, 94-106 (1950).

48. Reed, S. A., and Kuehn, P. R., Clinton Engineering Works, Tennessee Eastman Corp., B-4.380.32 (1946).

49. Rider, B. F., St. John, C. V., and Mellon, M. G., Purdue UnIversity, A-2708 (1946).

50. Roberts, L. E. J., and Seath, A., National Research Council of Canada, CI-151 (1947).

51. Rodden, C. J., Anal. Chem., 21, 327-35 (1949).

52. Rodden, C. J., "Analytical Chemistry of the Manhattan Project," ch. 1, New York, McGraw-H111 Book Co., Inc. (1950).

53. Rodden, C. J., et al., "Colorimetric Determination of Tuballoy by Alkaline Peroxide, "V-1016.

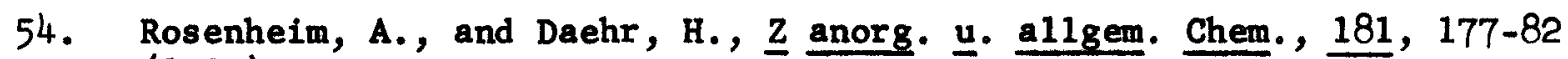
(1929).

55. Ibid., 208, 81-94 (1932).

56. Sande11, E. B., "Colorimetric Determination of Traces of Metals," p. $436 \mathrm{ff}$. New York, Interscience Pub1ishers, Inc. (1944).

57. Schwebel, A., National Bureau of Standards, NBS-202 (1948).

58. Scott, T. R., Analyst 74, 486-91 (1949). 
59. Scott, To Ro, Nature 163, 768-69 (1949)。

60. Scott, T.R., Analyst 75, 100-04 (1950)。

61. Smales, A. A. Imperial Chemical Industries, Ltd, Bilingham Div., England, BR-526 (1944).

62. Smales, A. A, and Furby, E。, Atomic Energy Research Establishment, Harwe11, England, AERE-C/R-344 (1949)。

63. Smales, A. A. and Furby, E. Nature 164, 579 (1949)

64. Stewart, G. M。, Widner, J。 $A_{\circ}$, and Gates, Jr., J. W., Clinton Engineering Works, Tennessee Eastman Corp。, CD-4019 (1945)。

65. Taylor, C。C。, Mallinckrodt Chemical Works, unpublished work (1945).

66. Treibacher Chemische Werke, A. G。, Karnten, Austia, Metall u. Erz, 40, 167 (1943)。

67. University of Rochester, $\underline{M}-\underline{1527}$.

68. Waldron, H. F。, and Dowdy, J。D。 Process Development Quarter ly Progress

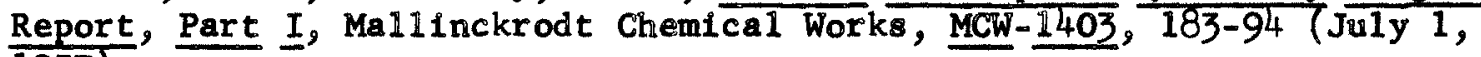
1957)。

69. Weaver, B。S。, Wick, $L_{0} B_{0}$, Woodard, $R_{0} W_{0}$, and Gates, Jr。, JoW., Clinton Engineering Works, Tennessee Eastman Corp。, CD-4020 (1945).

70. Winkler, Jo Ze1ss Nachrichten, 3, 160 (1939)。

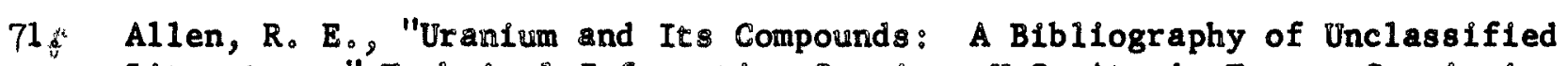
Literature," Technical Information Service, U.S.Atomic Energy Commission, TID-3041 (1953)。

72. Brackenbury, G., "Report on Rapid Colorimetric Method for Uranium Analysis, to be Used in Plant Control Work," Dept. of Mines and Technical Surveys, Mines Branch, Ottawa, Canada, NP-1939, TR-75/51 (1951)。

73. Burstal1, $\mathbb{F}_{0} G_{0}$, and Ryan, $W_{\circ}$ " "Chemical Methods for Estimation of Uranium in Mineral Products," Dept of Scientific and Industrial Research, Chemical Research Laboratory, Teddington, Middlesex, CRL-AE-1 (1950).

74. Burstall, $F_{0} H_{\circ}$, and Williams, $A_{0} \mathbb{F}_{\circ}$ "Handbook of Chemical Methods for the Determination of Uranium in Minerals, and Ores," London, His Majesty's Stationery office (1950).

75. Caley, E。 R。, and Foulk, CoW。 "A Gravimetric and Colorimetric Method for the Direct Determination of Sodium," J. Am. Chem. Soc., 51, 1664-74 (1929). 
76. Canadian Bureau of Mines, "The Spectrophotometric Determination of Uranium" (1946).

77. Casto, C., Eyley, No, Smellie, Jr。, R. H., and Price, T。 D。, "Manual of Standard Analytical Methods," Clinton Englneering Works, Tennessee Eastman Corpo, CD-3801 (1945).

78. Croxton, F. E., "Uranium and Its Compounds: A Bibliography of Unclassified Literature," Oak Ridge Installation, Carbide and Carbon Chemicals Co., K- 295 (1951)。

79. Fairley, T., "On the Detection and Separation of Minute Quantities of Hydrogen Dioxide and of Uranium," Chem. News, 62, 227 (1890).

80. Fairley, T., "Sodium and Uranium Peroxides, etc.," Nature 50, 103-104 (1894)。

81. Gaudin, A. Mo, et al., "The Recovery of Uranium from Low Grade Ore," J. Met. Ceram., No. 5, 38-53 (1950)。

82. Gaudin, A. Mo, et al., "The Recovery of Uranlum from Low Grade Ore," Massachusetts Institute of Technology, MITG-243 (1950)。

83. Gessiness, B., "Manual of Analytical Procedures," National Lead of Ohio, FMPC-69, Vol。I (1952)。

84. Gilbreath, J。R., and Simpson, O.C. "Summary Report for January, February, and March, 1951," Argonne National Laboratory, University of Chicago, ANL-4613 (1951)。

85. Goldbeck, C. G., and Rodden, C. J., "Colorimetric Determination of Uranlum and Its Application to Low Grade Ores," National Bureau of Standards, Analytical Chemistry of the Manhattan Project Collected Papers, No. 38 .

86. Grimes, W。 R。, and Clewett, GoH., "Procedures for Raw Materials Analysis at $Y-12, "$ Oak Ridge Installation, Carbide and Carbon Chemicals Co., Y-465 (1949)。

87. Ljunggren, G., Rynninger, $R_{0}$, and Sillen, L. G., "Determination of Small Quantities of Uranium. A Critical Discussion of Methods Previously Used and a General Survey of the Present Investigation," Svensk Kem. Tid., $61,170-180$ (1949).

88. Rabbits, F. To, "Determination of Uranium in Ores. Review of Chemical Methods," Dept. of Mines and Technical Surveys, Ottawa, Canada, Mines Brach Memorandum Series No. 109 (Atomic Energy Commission File No. NP-1890) (1950). 
89. Rabbits, F. T., "Determination of Uranium in Ores. Review of Chemical Methods," Trans. Can. Inst. Mining Met. 55 (In Can. Mining Met. Bull. No. 477) $2 \overline{7-29}$ (1952).

90. Rodden, C. J., "Analytical Chemistry of Uranium," Anal. Chem. 25, 1598-1601 (1953).

91. Rodden, C. J., and Tregoning, J. J., "Manual of Analytical Methods for Determination of Urantum and Thorium in Their Ores," U.S. Government Printing Office (1950).

92. Ibid., revised (1955). 


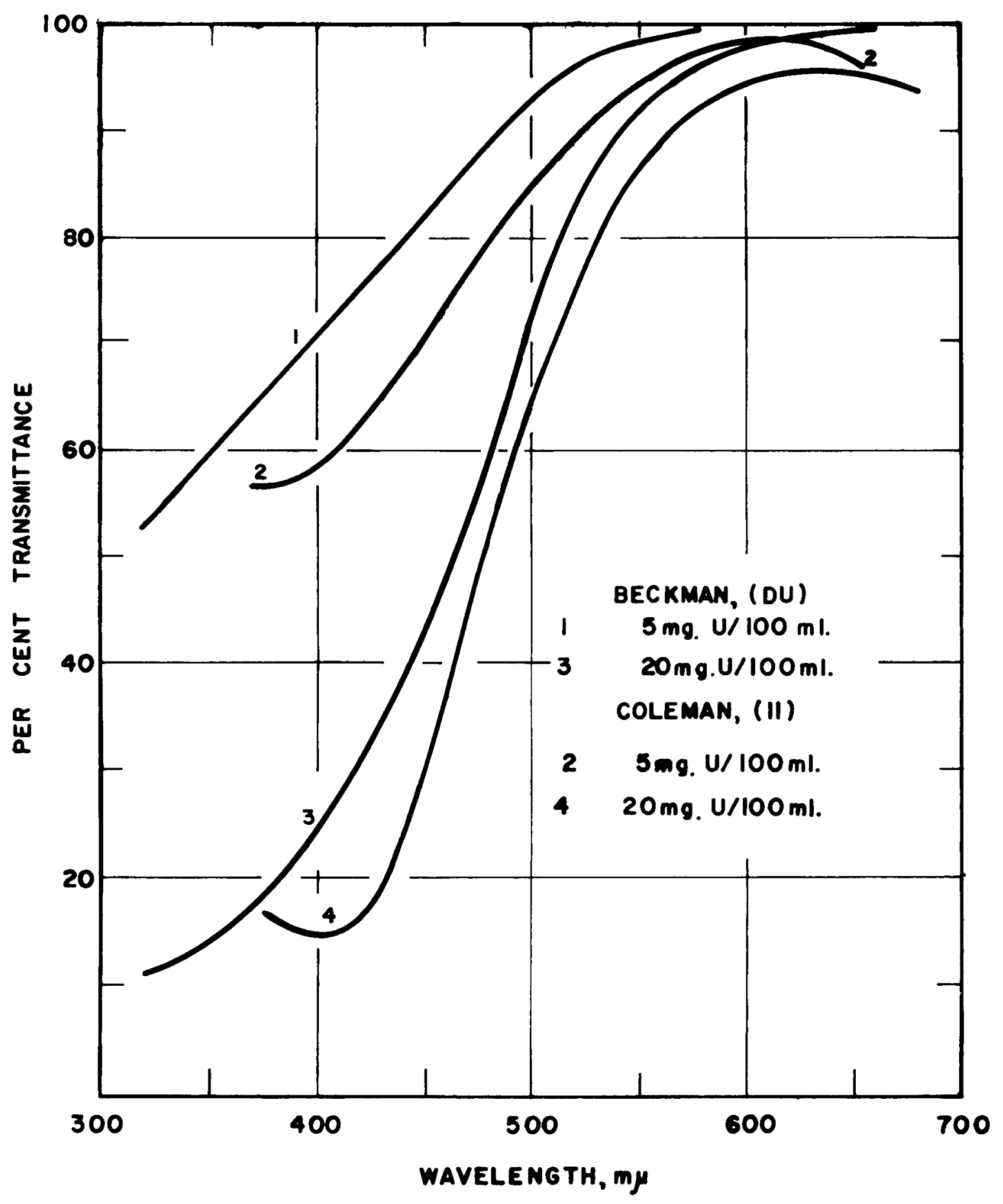

Fial. SPECTRAL tRANSMitTANCE CURVES FOR THE $\mathrm{Ne}_{2} \mathrm{CO}_{3}-$ $\mathrm{H}_{2} \mathrm{O}_{2} \mathrm{U}$ SYSTEM, MEASURED AGAINST WATER BLANKS $(30)$. 


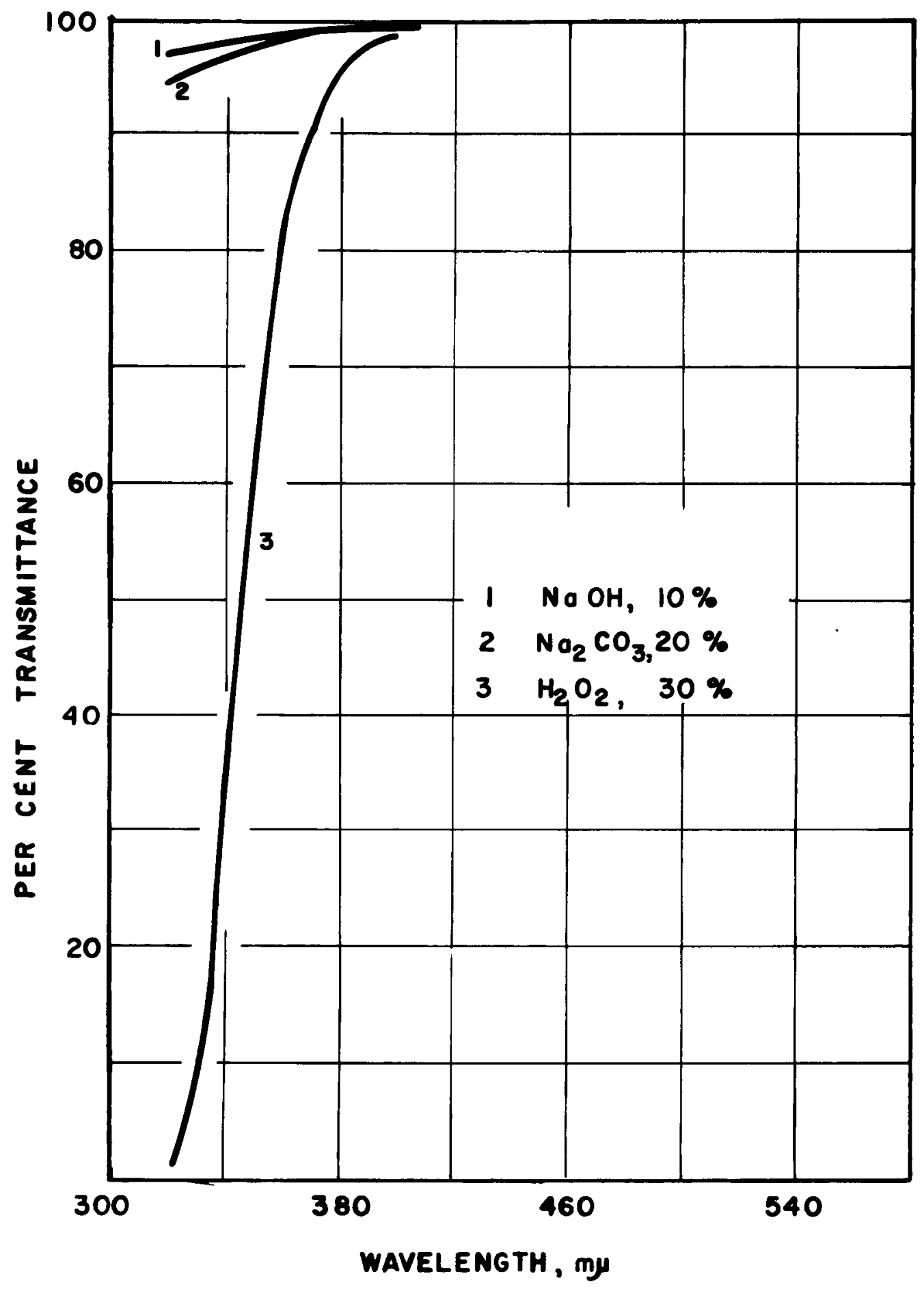

FIG. 2 SPECTRAL TRANSMITTANCE CURVES FOR $\mathrm{NoOH}, \mathrm{NO}_{2} \mathrm{CO}_{3}$, AND $\mathrm{H}_{2} \mathrm{O}_{2}$, MEASURED WITH THE BECKMAN (DU) IN $1-\mathrm{cm}$. CELLS AGAINST WATER BLANKS (49). 


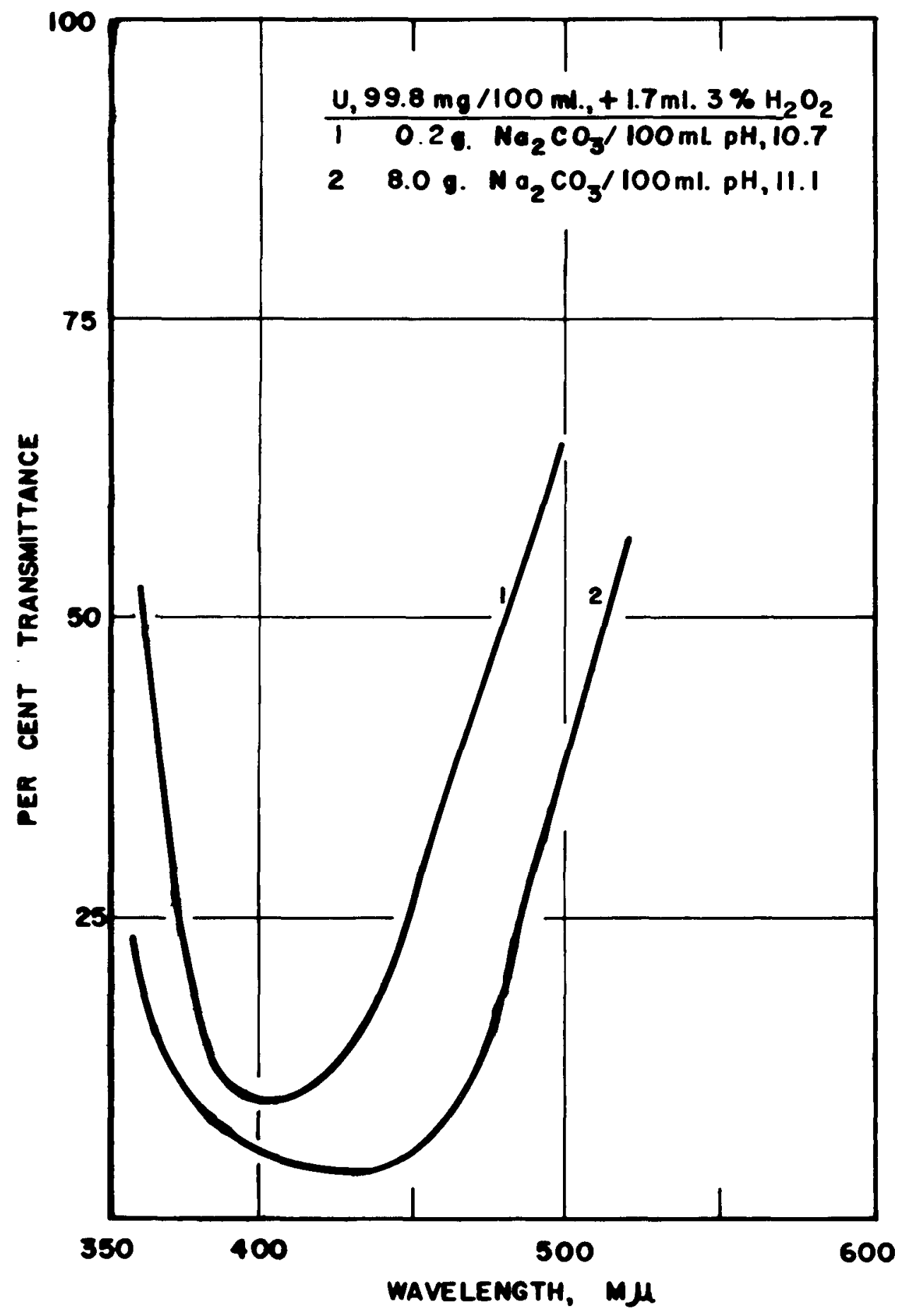

FIG.3. THE EFFECT OF THE SODIUM CARBONATE CONCENTRATION ON THE SPECTRAL tRANSMITTANCE OF THE $U-\mathrm{H}_{2} \mathrm{O}_{2} \mathrm{NO}_{\mathrm{CO}} \mathrm{CO}_{3}$ SYSTEM USIMG THE CENGO SPECTROPHOTELOMETER ANO BLANKS CONTAINING ALL MATERAL EXCEPT THE PEROXIOE (O). 


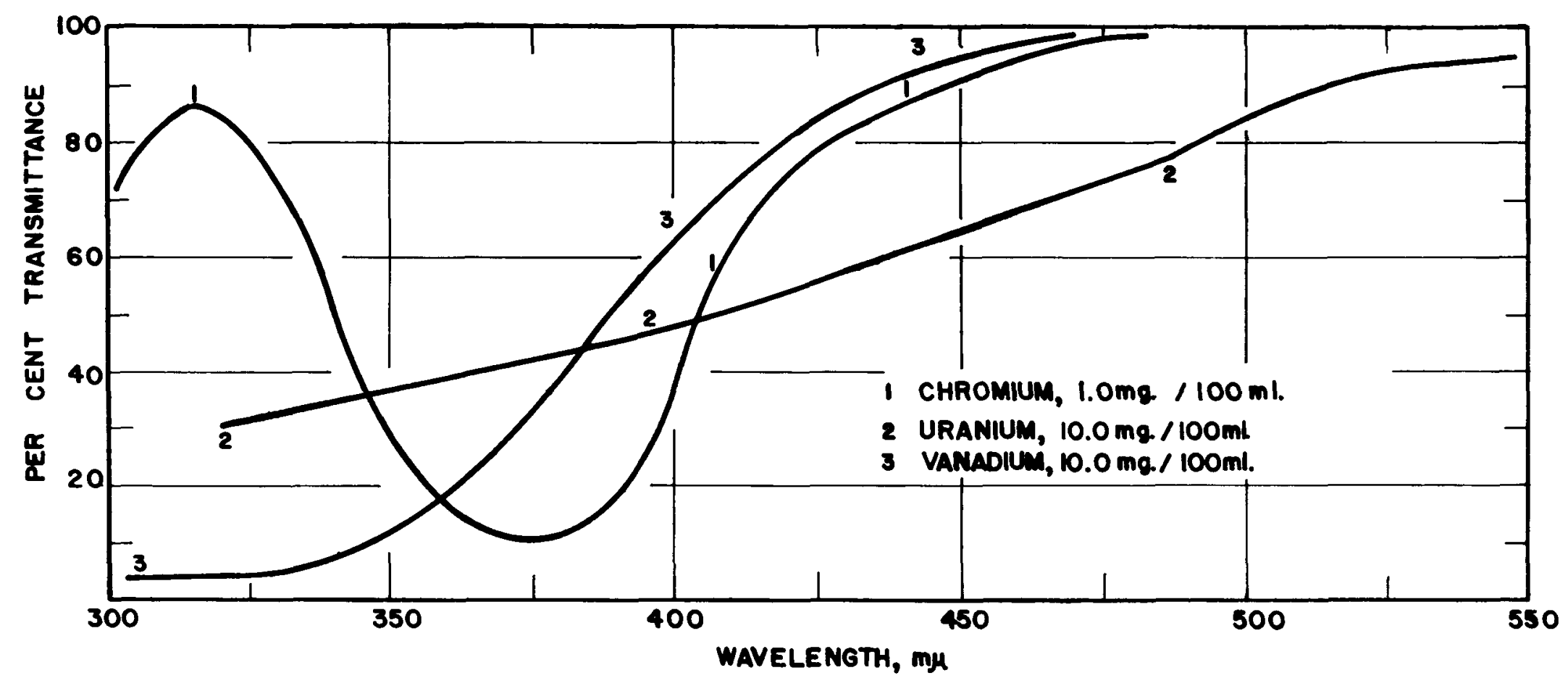

FIG. 4. SPECTRAL TRANSMITTANCE CURVES FOR $\mathrm{U}, \mathrm{V}$, AND $\mathrm{Cr}$ IN A $\mathrm{Na}_{2} \mathrm{CO}_{3}-\mathrm{H}_{2} \mathrm{O}_{2}$ SYSTEM, USING A BECKMAN (DU) WITH HCM. CELLS AND WATER BLANKS (30). 


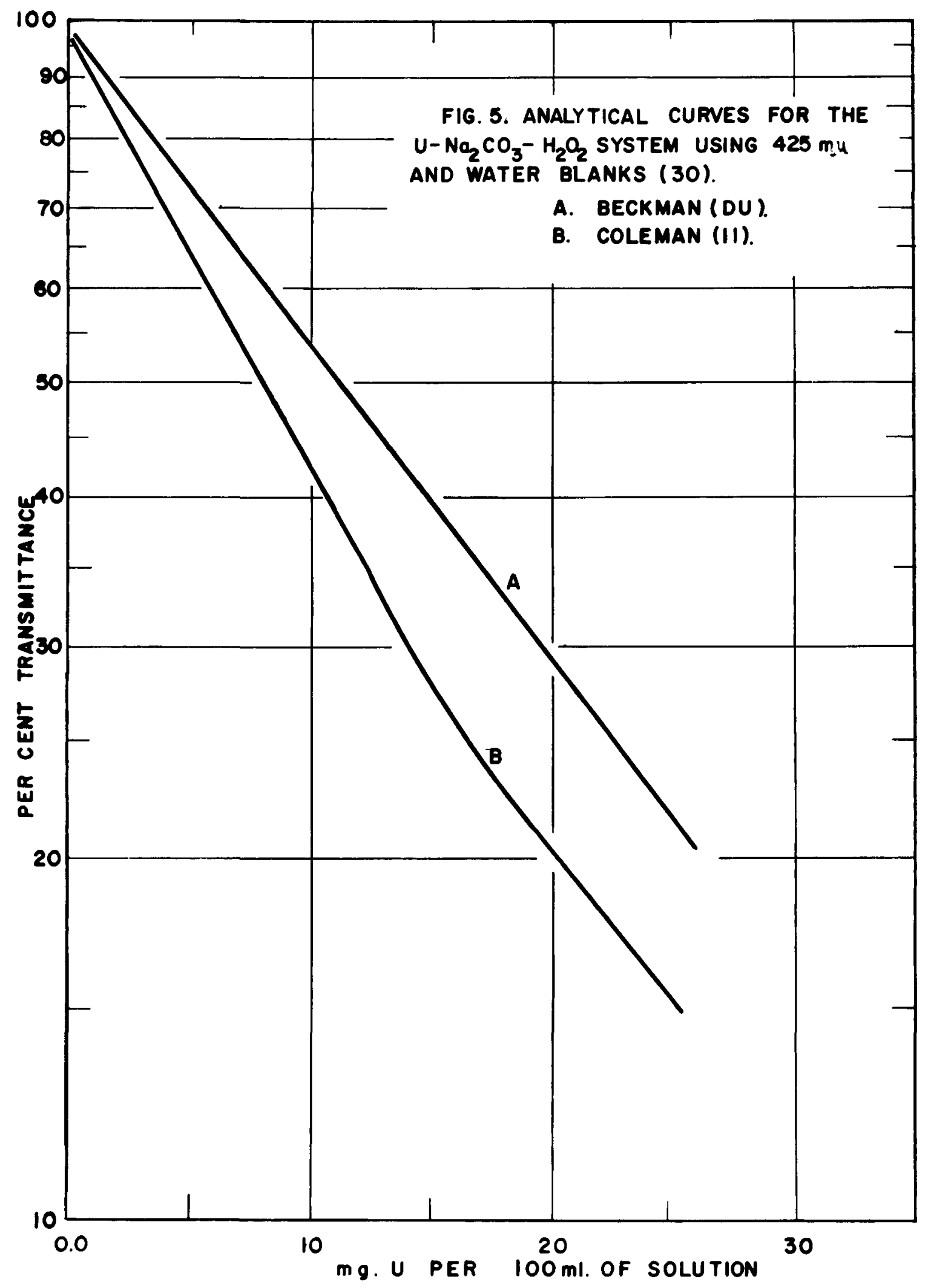




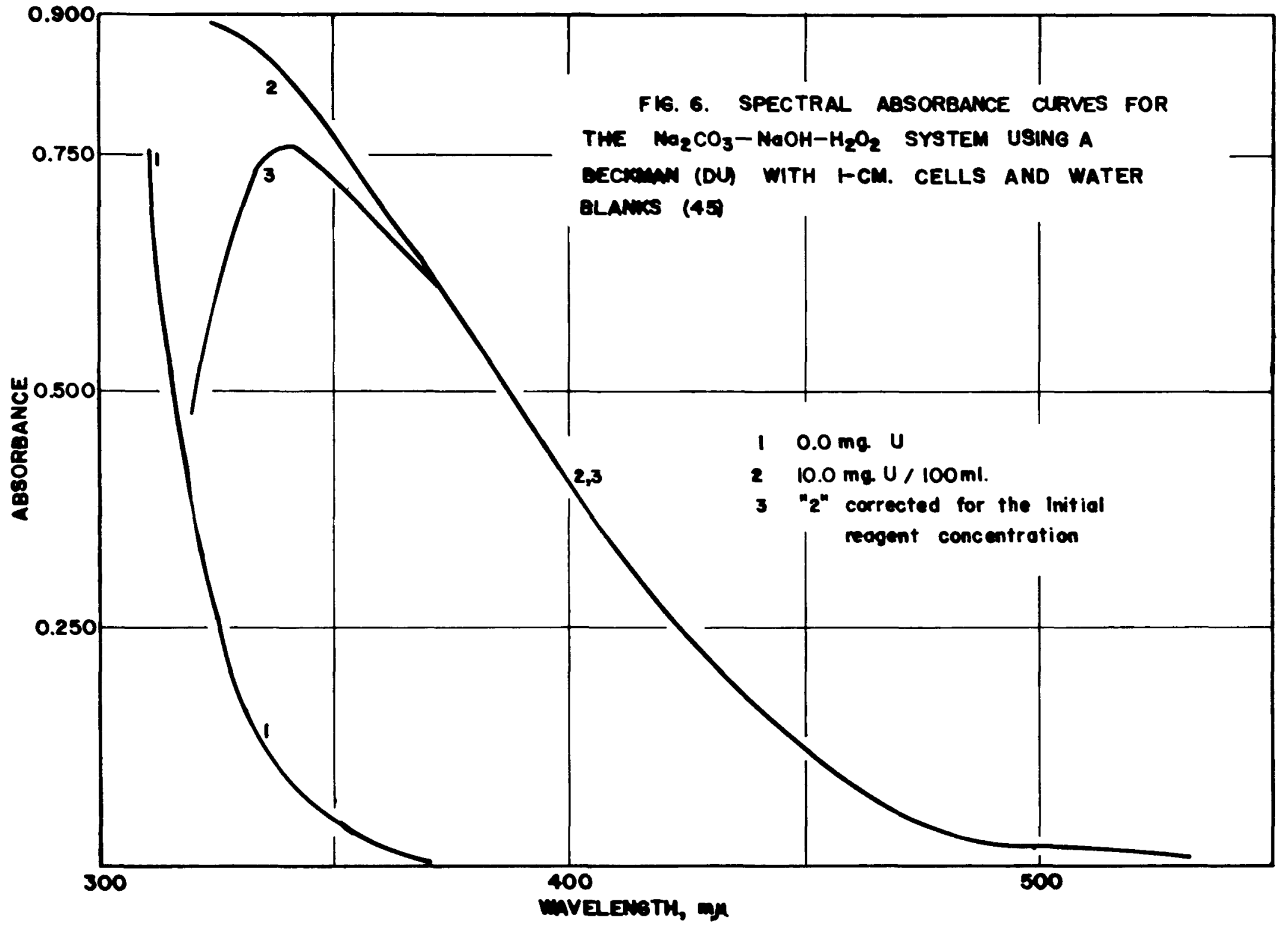




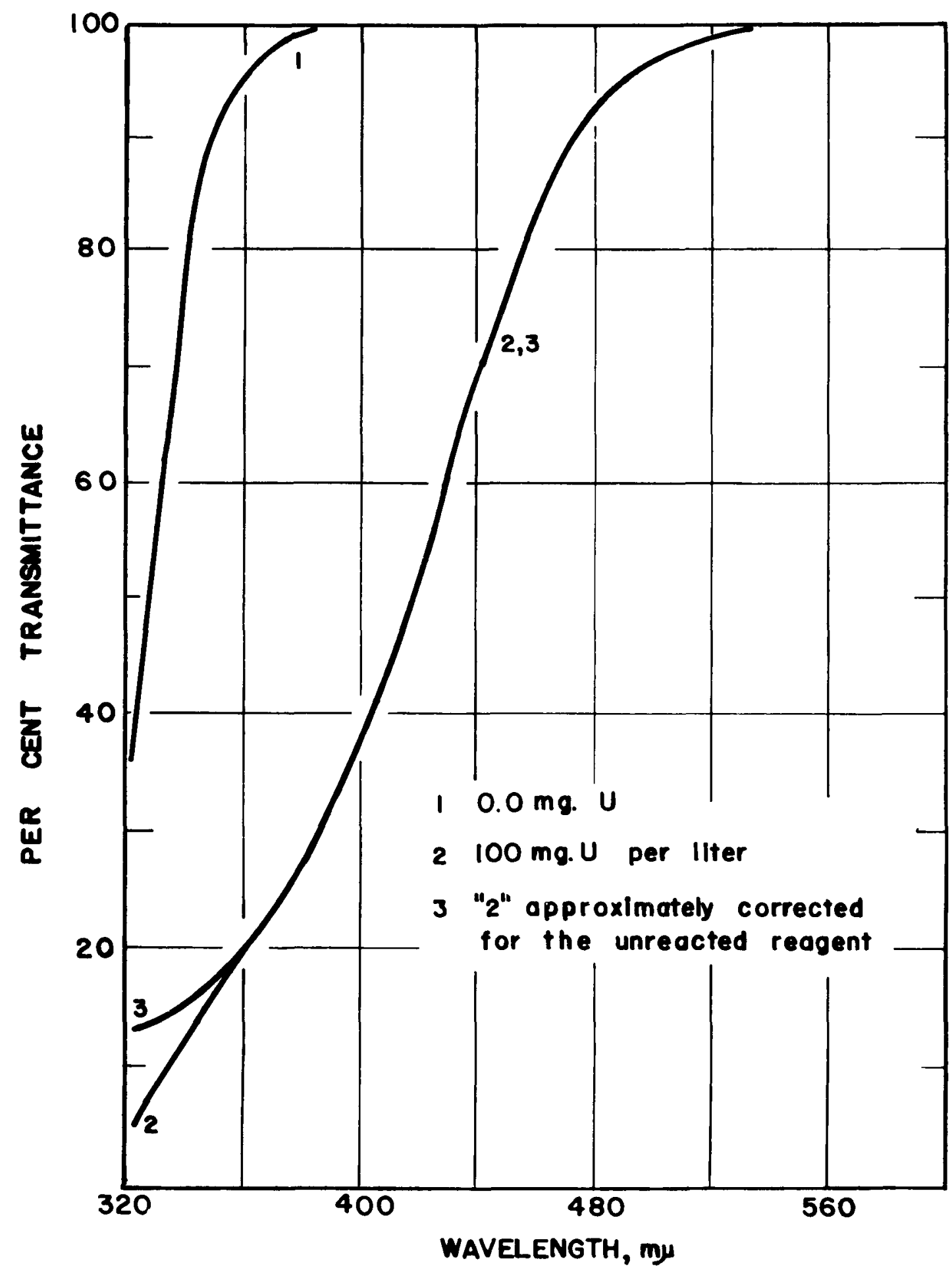

F1G. 7. SPECTRAL TRANSMITTANCE CURVES FOR THE $\mathrm{Na}_{2} \mathrm{CO}_{3}-\mathrm{NOOH}-\mathrm{H}_{2} \mathrm{O}_{2}$ SYSTEM USING A BECKMAN (DU) WITH I-CM. CELLS AND WATER BLANKS (49). 


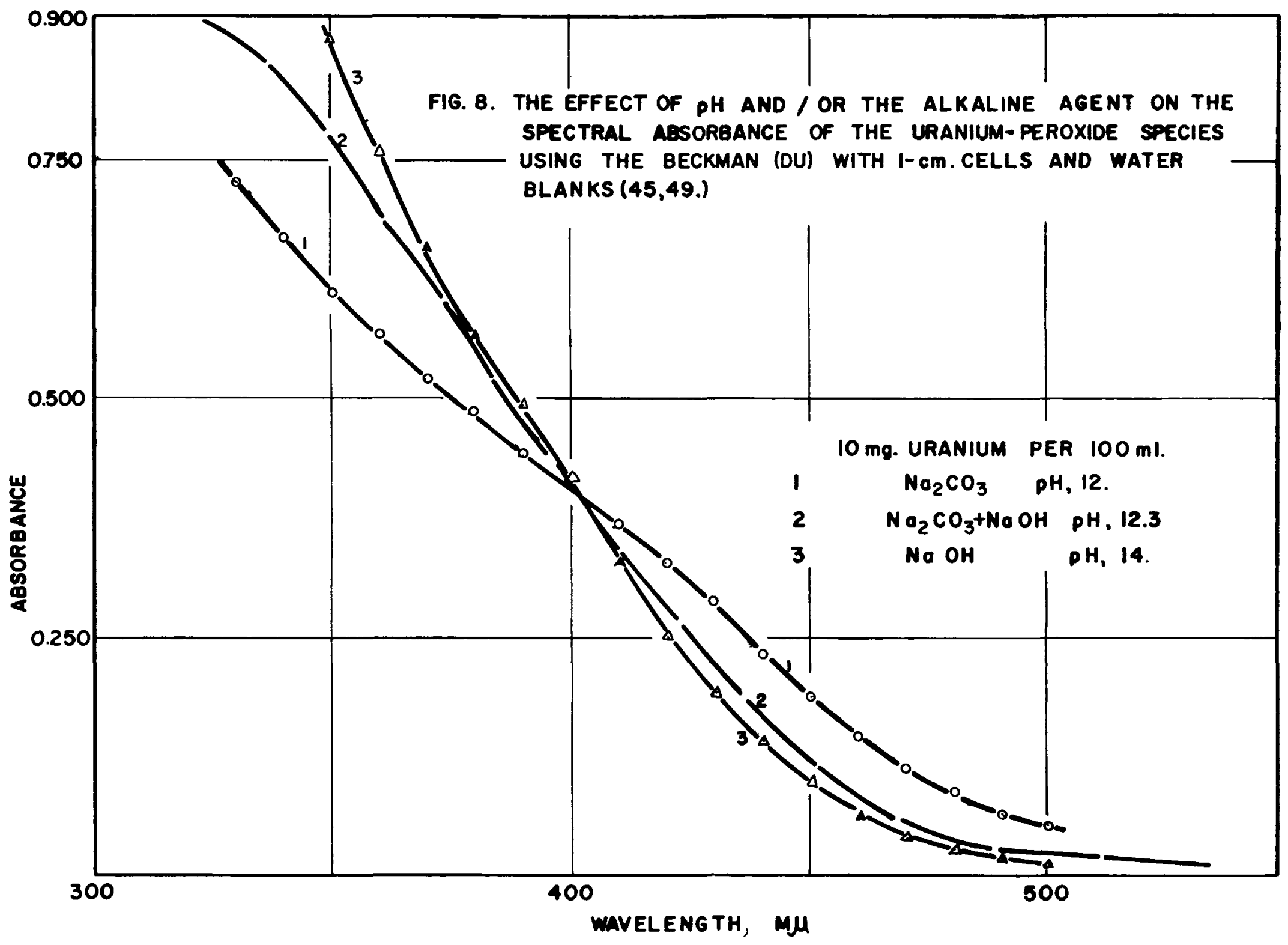


59

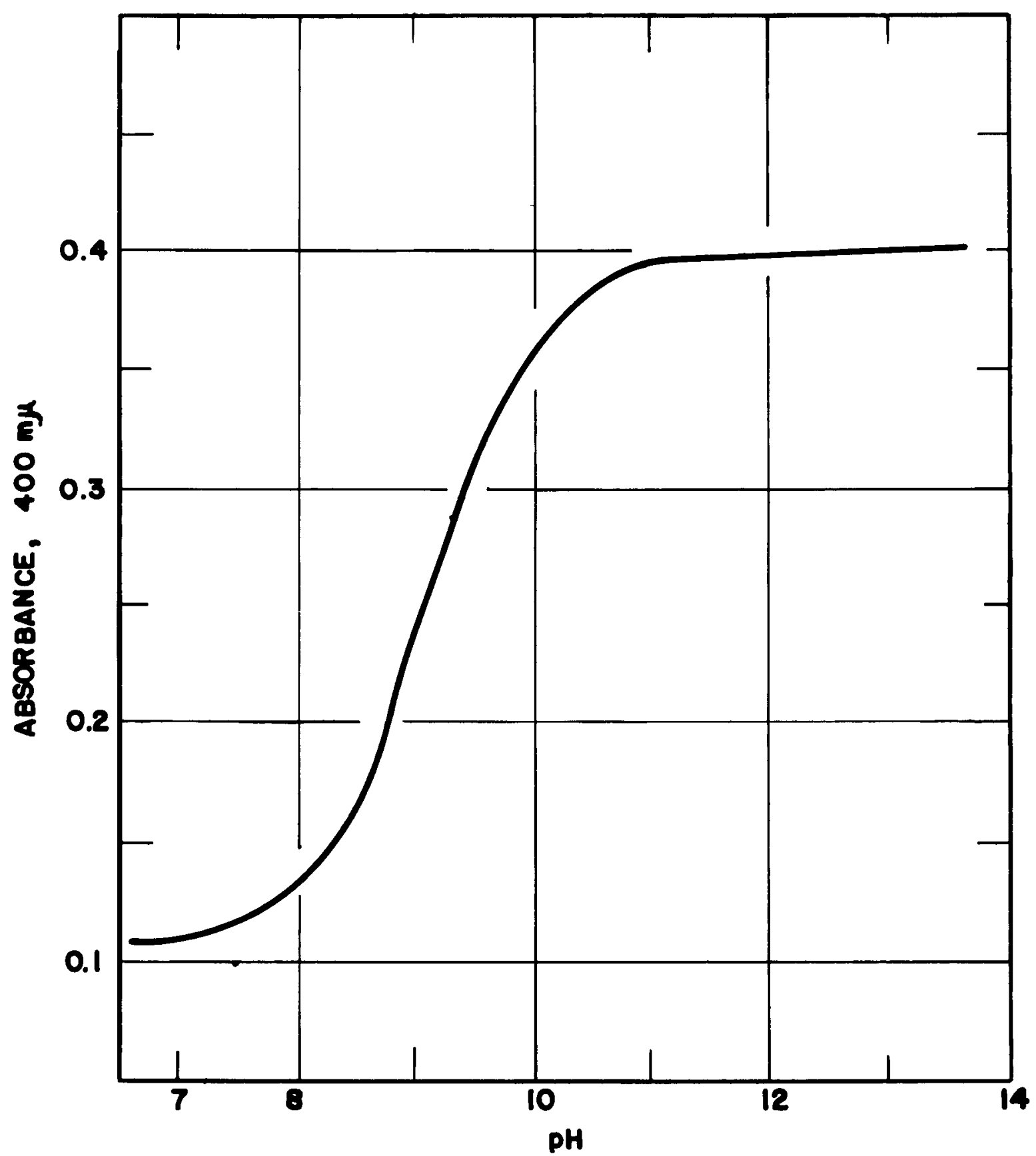

FIG. 9. THE VARIATION OF ABSORBANCE OF THE URANIUM-PEROXIDE SPECIES WITH PH IN THE $\mathrm{Na}_{2} \mathrm{CO}_{3}-\mathrm{NaOH}$ SYSTEM USING THE BECKMAN (DU) WITH 1-CM. CELLS AND WATER BLANKS. THE SOLUTIONS CONTAINED Q. mg. U/ml. (49). 




F16. 10. SPECTRA TRANSMITTAMCE CUAVES FOn THE NOOH- $\mathrm{H}_{2} \mathrm{O}_{2}-\mathrm{U}$ SYSTEM USHO THE BECKMAN (DU) MTH hoM. CEus and mater olanks (30). 


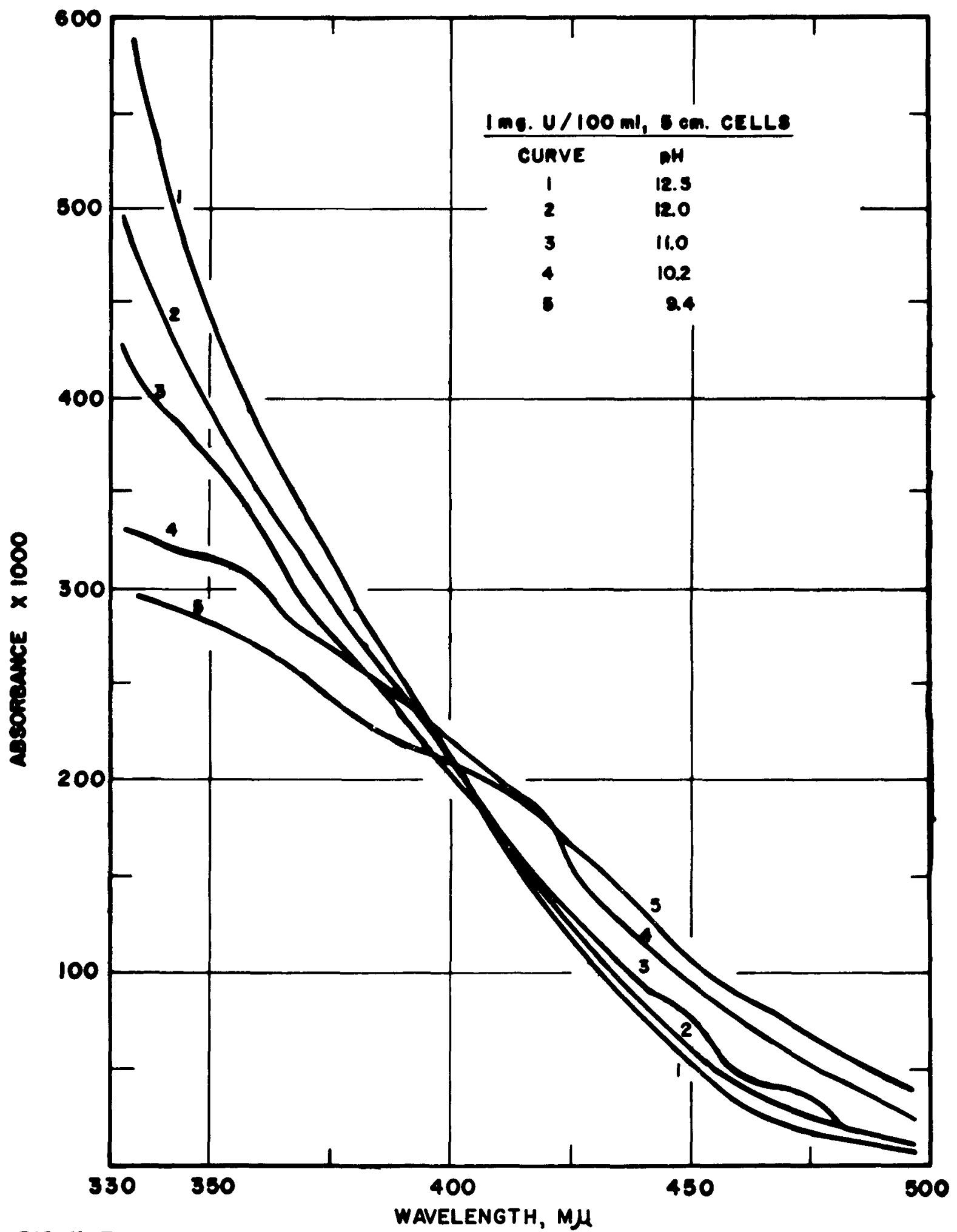

F16. II. THE EFFECT OF PH ON THE SPECTRAL ABSOROANCE OF THE NOOHMOU S SYSTEM USING THE BECKMAN (DU) SPECTROPHOTOMETER (OO). 


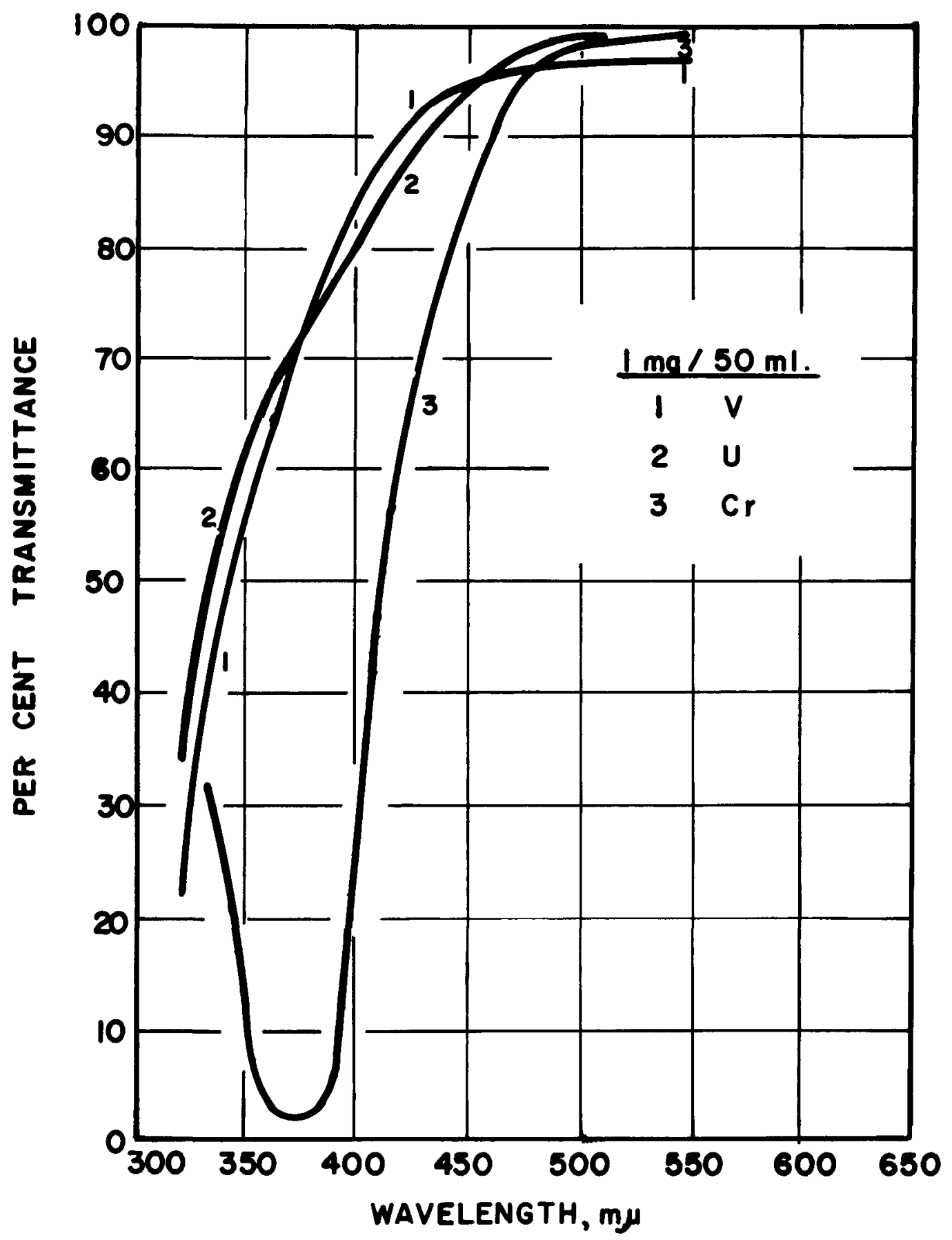

FI6.12. SPECTRAL TRANSMITTANCE CURVES FOR U, V, AND $\mathrm{Cr}$ IN A NOOH- $\mathrm{H}_{2} \mathrm{O}_{2}$ SYSTEM USING A BECKMAN (DU) WITH 1-CM.CELLS AND WATER BLANKS (10). 


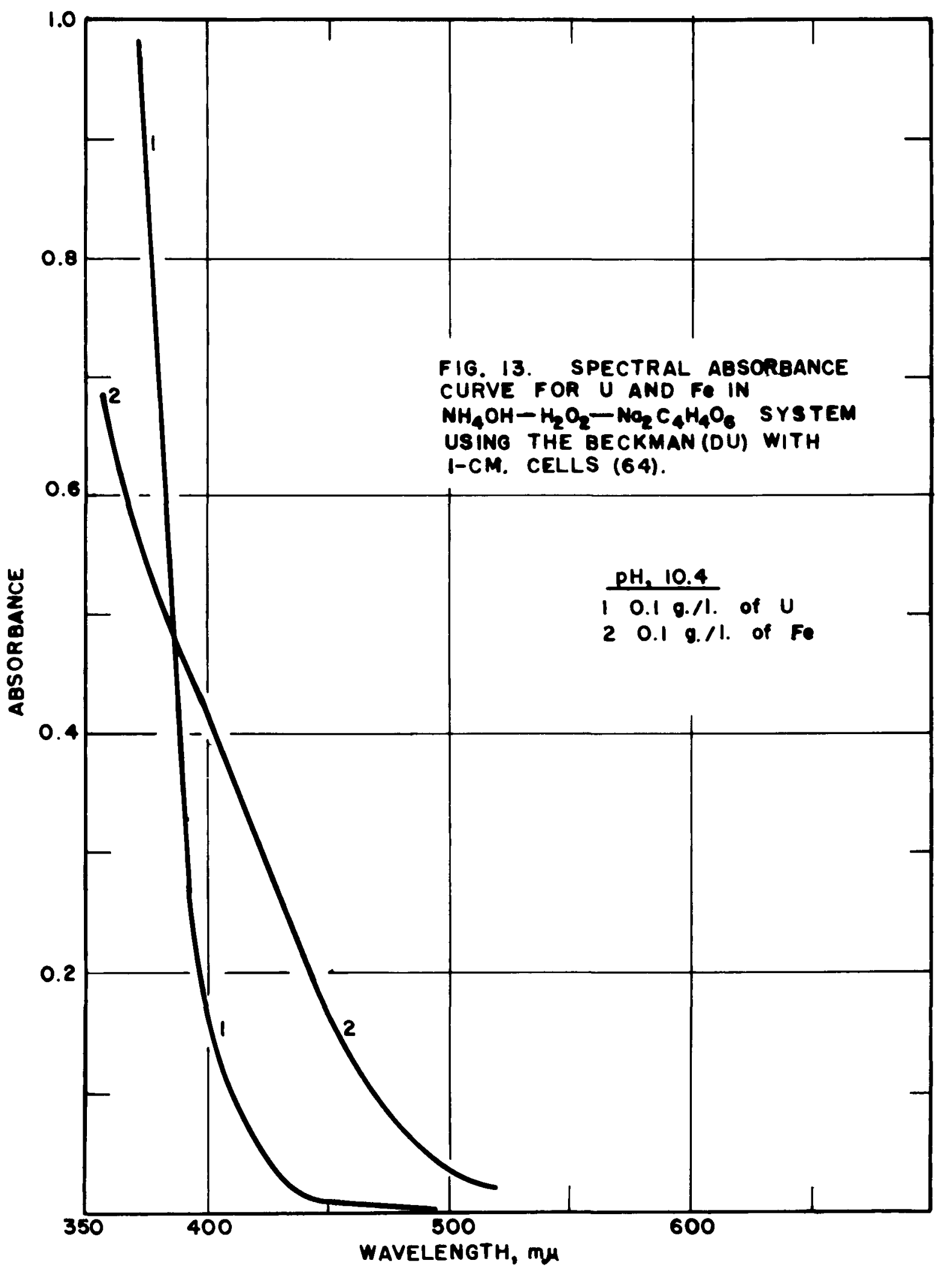

